\title{
Do Conservation Policies Work? Evidence from Residential Water Use *
}

\author{
Oliver R. Browne, Ludovica Gazze, Michael Greenstone
}

September 9, 2020

\begin{abstract}
In response to the historic 2011-2017 California drought, local governments enacted a raft of conservation policies and little is known about which ones explain the sharp decline in residential water consumption. To answer this question, we use a novel data set of hourly water consumption data for over 82,300 households in Fresno, California where water consumption declined by nearly a third and have three main findings. First, we estimate the price elasticity of demand for water to be 0.16 for marginal rates and 0.39 for average rates. Second, reducing the number of days where outdoor watering is allowable from 3 to 2 substantially decreases water use, despite the availability of opportunities to substitute between permitted and non-permitted hours, days, and seasons. Third, "bully pulpit" pronouncements about the water crisis increased public awareness of drought conditions but did not contribute to water savings. Overall, higher water prices explain 40-44\% of the changes in residential water use observed during our sample period in Fresno and reductions in the number of days when outdoor watering is allowable explain $45-51 \%$ of these changes. However, the absence of experimental or quasi-experimental variation in these policies means that we interpret this associational evidence cautiously.
\end{abstract}

*Contact: Oliver Browne: oliver.browne@berkeley.edu; Ludovica Gazze: lgazze@uchicago.edu; Michael Greenstone: mgreenst@uchicago.edu. We thank Laura Grant, Matt Kotchen, Casey Wichman, and participants at the EPIC Lunch seminar, AERE, ASSA, and NBER EEPE conferences for helpful comments. We also thank Bridget Pals, Iris Song, and Jackson Reimer who provided excellent research assistance. This paper would not have been possible without the endless support from our partners in Fresno to help us understand their programs, in particular we thank Tommy Esqueda, Bud Tickel, Cheryl Burns and Nora Laikam. All remaining errors are our own. 


\section{Introduction}

Environmental goals, such as resource conservation, can be achieved through a range of price and nonprice instruments. However, during crises, policymakers may be forced to adopt multiple policy changes simultaneously to induce urgent behavior change and achieve policy goals. Simultaneous policy changes make it challenging to estimate the impact of individual actions ex-post. As a result, it is unclear what mix of policies most effectively change behavior under such conditions. While economic analysis may favor using prices to manage demand, price instruments may be untenable for political and equity considerations (Olmstead and Stavins, 2009).

We study this issue in the context of water conservation. It is vital for utilities to understand which policies effectively induce water conservation, especially as climate change is expected to increase the frequency and severity of droughts in arid regions worldwide. Moreover, these droughts will likely be exacerbated by growing populations and increased costs of developing new supply. Between 2011 and 2017, California experienced an unprecedented drought, by some measures the worst in over 1,200 years (Griffin and Anchukaitis, 2014). As shown in Figure 1, the United States Department of Agriculture measured a record $78 \%$ of the state to be in either 'Extreme' or 'Exceptional' drought. ${ }^{1}$ In an attempt to reduce residential water consumption, utilities deployed a range of policies: they raised water rates, introduced or tightened outdoor water use restrictions, and funded public awareness campaigns. Further, California Governor Jerry Brown declared a State of Emergency in January 2014, which culminated in an April 2015 mandate that utilities reduce water use by $25 \%$ relative to a 2013 baseline. The policies adopted by utilities were surprisingly successful in acheiving their stated goals, $43 \%$ of Californian utilities achieved their State-mandated conservation goal; but, there is little, if any, systematic evidence on which policy levers were most effective at reducing water consumption and their relative efficiency.

This paper seeks to answer this question by disentangling the effect different state and municipal policies had on residential water use in the 2011-2017 California drought. We use hourly water use data from over 82,300 single-family households in Fresno, California, between 2013 and 2016. Fresno is one of the very few large cities that has universally adopted advanced metering infrastructure or 'smart meters' that communicate continuously with the utility. Hourly data from these meters allow us to estimate the differential impacts of policies across different hours of the day, which is crucial to study compliance with regulations that schedule when outdoor water use is permitted. Figure 2 shows that water use in 2013 in Fresno was comparable to California as a whole (per capita consumption of 132 gallons per day for Fresno versus

\footnotetext{
1 "Extreme drought" and "Exceptional drought" are the two most extreme of the five levels of drought classification measured by the USDA drought monitor. An area experiences "Extreme drought" when major crop areas and pasture losses are common, fire risk is extreme and widespread water shortages can be expected. An "Exceptional drought" is the most severe category of water shortage that, in addition to the traits of Extreme drought, result in water emergencies.
} 
138 gallons per day statewide), suggesting that Fresno can offer a useful case study to learn about water conservation policies elsewhere in California. We link these data with city-level weather and precipitation data to control for daily variation in temperatures and precipitation that could affect water use.

Our four-year sample period is an appealing period to study the efficacy of water conservation policies in Fresno. In this period, Fresno implemented a suite of water conservation policies, including six rate changes and a reduction in the number of days that households could use water outdoors. Specifically, marginal rates increased twice between January 2013 and August 2014. The second rate increase sparked backlash among customers, leading the City to temporarily reduce both marginal and fixed rates. After a new rate-setting process, marginal rates were increased again, fixed rates decreased, and further annual increases to both rates were planned into the future. At the end of 2016, fixed rates were similar to those at the beginning of 2013, whilst marginal rates had more than doubled. The backlash against the rate increase in August 2014 suggests that these rate changes were salient. Further, two state-level regulatory announcements related to the drought occurred in this period: the State of Emergency declaration in January 2014, and the April 2015 mandate requiring all utilities to reduce water use by $25 \%$ relative to a 2013 baseline. Importantly, per household water consumption in Fresno declined by 136 gallons per day or 32.8\% between 2013 and 2016 .

Water use is highly seasonal, peaking in summer as outdoor irrigation increases. From 2013 to 2015, water use decreases year on year in Fresno, a trend that stops in 2016 as the drought eased (Figure 3). This seasonality coupled with the simultaneity of the policies implemented to reduce water use makes it challenging to disentangle the policies' individual impacts. Our empirical analysis controls for seasonality using week-of-year fixed effects and weather controls. Our preferred specification does not include year fixed effects, because, given our relatively short time frame, the fixed effects absorb important variation in outcomes necessary to identify the effects of the policies of interest. The absence of year fixed effects means that we interpret the results with some caution; however, we also report estimates from specifications that include year fixed effects. ${ }^{2}$

There are three main findings. First, we find a 0.16 elasticity with respect to marginal price and a 0.39 elasticity with respect to average price. Rate changes account for 40-44\% of household water savings in Fresno between the first half of 2013, before any change in policy occurred, and the year 2016. It is noteworthy that our estimated price elasticity of demand of water is consistent with the previous literature on the elasticity of demand for water and electricity (Jessoe and Rapson, 2014; Labandeira, Labeaga, and López-Otero, 2017; Baerenklau, Schwabe, and Dinar, 2014; Klaiber et al., 2014; Nataraj and Hanemann, 2011; Olmstead, 2009; Olmstead, Hanemann, and Stavins, 2007). Further, our findings also accord with

\footnotetext{
${ }^{2}$ A better research design might compare changes in water consumption in Fresno to another city that did not change its watering schedule on the same date. We attempted to secure data from comparable cities with different policies, but were unable to do so.
} 
recent literature estimating larger elasticities with respect to average rather than marginal prices (Ito, 2013; Ito, 2014; Wichman, 2014).

Second, we study a change in the outdoor water schedule regulations that reduced the number of days that outdoor water use was permitted during the summer. After adjustment for all other policies, we find that summer water consumption significantly declined after the summer restrictions went into place. The estimated summer decline in water use associated with the schedule change accounts for $45-51 \%$ of the total water savings between the first half of 2013 and the year 2016. However, we note that there is also a decline in winter water use in the same period, although the winter outdoor watering policy was unchanged. ${ }^{3}$ Without experimental or even quasi-experimental variation in the policy, we cannot decisively determine whether the decline in winter water consumption is due to persistent behavior changes such as lawn replacements or reflects confounding factors such as secular trends that also explain the summer reduction.

Our unique hourly water use data allow us to shed light on the effects of non-price instruments like watering restrictions on times when the restrictions do and do not bite. On the one hand, we find evidence of spillover effects on unrestricted times, in line with evidence suggesting that restrictions increase the salience of conservation behavior (Pratt, 2019). On the other hand, we document that intertemporal substitution of water use reduces the environmental benefits of the restrictions. These findings parallel the mixed evidence on the impact of automobile driving restrictions based on license plate numbers due to substitution across times and vehicles (Davis, 2008; Viard and Fu, 2015; Zhang, Lawell, and Umanskaya, 2017). Despite the high implied disutility associated with the restrictions, which may result in lower overall welfare (Hensher, Shore, and Train, 2006; Baumol, 1988; Grafton and Ward, 2008; Mansur and Olmstead, 2012), mandated restrictions can effectively reduce water use, depending on the information content and enforcement strength (Pratt, 2019; Wichman, Taylor, and Haefen, 2016; Halich and Stephenson, 2009; Kenney, Klein, and Clark, 2004; Renwick and Green, 2000; Michelsen, McGuckin, and Stumpf, 1999; Castledine et al., 2014).

Third, we observe that after the "State of Emergency" and "Mandated Reductions" announcements, interest in the California drought increases, as measured by a Google search index for the keyword "drought". However, this increased awareness does not appear to have contributed substantially to the realized water savings in Fresno during our sample period. While non-price instruments such as behavioral nudges, social norms, and moral persuasion may help correct mistakes and improve welfare under imperfect information (Allcott, 2016; Asensio and Delmas, 2015; Ito, Ida, and Tanaka, 2018; Ferraro and Price, 2013), our findings complement research showing that targeted marketing campaigns can raise public awareness of an issue,

\footnotetext{
${ }^{3}$ When the total reduction in water use throughout the year is treated as the impact of the change in summer water schedule regulations, then the policy appears to explain $92 \%$ of the observed water savings and the sum of the savings explained by each policy becomes larger than the total water savings observed over our sample period. Since the decrease in winter consumption is comparable to the summer decline, we would conclude that the reduction in outdoor watering days did not explain any of the observed water savings if both are due to a confounder.
} 
yet may not change behavior (Syme, Nancarrow, and Seligman, 2000). Moreover, our findings contrast with previous literature on social norms and water use that shows, for example, that peer comparisons and injunctive messaging effectively reduce resource use (Ferraro, Miranda, and Price, 2011; Brent, Cook, and Olsen, 2015; Bhanot, 2018; Jessoe et al., 2018; Allcott and Rogers, 2014; Allcott, 2011).

This paper analyzes the relative effectiveness of different conservation policies at reducing water use. The breadth of the data that we collected is rare and allows for this analysis. Our hourly water meter data stand in stark contrast to the data collected by most utilities, which consist of a single meter reading every month or quarter. We also constructed a comprehensive timeline of all water conservation policies announced and adopted by the City of Fresno and the State of California during our sample period. The concurrence of several policies at one time reflects the messy detail of how policies are often implemented during a crisis, in a piecemeal fashion and simultaneously, with the hope that something sticks. In this paper, we take a step forward in disentangling the relative effectiveness of these policies.

The paper proceeds as follows: Section 2 describes the data. Section 3 examines the impact of each water policy adopted in Fresno on patterns of water use individually. Section 4 estimates the impact of conservation policies simultaneously and discusses the extent to which each policy explains the observed changes in water use during our sample period. Section 5 concludes.

\section{Data and Background}

We observe hourly water use between 2013 and 2016 for the universe of single-family households in Fresno, one of the five largest cities in California. In cleaning the data we drop all newly constructed houses, abandoned houses and households with a change of address during our sample period. We also drop all hours when smart-meter transmission malfunctions lead to implausible estimates of water use more than four standard deviations away from the city's average. This process leaves us with around 31,400 hourly observations for over 82,300 households. We link these data with daily temperature and precipitation data from the National Centers for Environmental Information within the National Oceanic and Atmospheric Administration.

To measure changes in public awareness of the drought over our sample period, we collect Google Trends data showing the relative popularity of Google searches related to "drought" between 2013 and 2016 at the weekly level in the Fresno-Visalia region. Our query returns a "Drought Interest" index between 0 and 100. The index takes a value of 100 at its peak number of searches in a given week and 50 when the term is half as popular. A score of 0 means that the number of weekly searches was less than $1 \%$ of the peak. We use this index to explain changes in water consumption as a result of public awareness of drought conditions. 
Figure 3 documents changes in average daily water use relative to the range of water conservation policies adopted in Fresno during our sample period. Water rates changed six times, with monthly fixed rates ranging between $\$ 11.20$ and $\$ 16.40$ and marginal rates varying between $\$ 0.82$ and $\$ 1.84$ per 1000 gallons. Moreover, in August 2014, Fresno reduced the number of days households were allowed to use water outdoors in the summer months from three to two. Finally, we note two public announcements during our sample period. On January 17, 2014, Governor Jerry Brown declared California to be in a State of Emergency as a result of the drought. This declaration allowed the state to access federal disaster relief funds and gave the State additional jurisdiction over local water institutions to manage water supply. On April 1, 2015, the State imposed unprecedented mandatory water use reductions, requiring all local water utilities to reduce water use by $25 \%$ relative to 2013 .

Appendix Table A.1 compares demographic and climate characteristics, as well as average water use, in Fresno with the top 100 water utilities in California. Appendix Figure A.1 maps the average maximum temperature and rainfall across all of California. Fresno is quite populous, albeit poorer than the rest of urban California. It ranks towards the middle third among the top 100 utilities for baseline water use, and it registers rainfall and low temperatures that are close to the average for the state, although its daily high

temperatures are among the highest. In general, Fresno offers a reasonable case study for other cities in California and the US South.

\section{Empirical Estimates of Water Conservation Policies on Con- sumption}

This section considers the impact of water conservation policies implemented in Fresno individually and separately estimates their impacts on household water use. Specifically, we study the impact of 1) rate changes, 2) a reduction in the number of outdoor watering days, and 3) state-wide regulatory announcements. In section 4, we pool all of these policies together to estimate their simultaneous impact.

To evaluate each policy, we employ different empirical approaches depending on the identifying variation generated by its implementation. In general, we use an event-time framework, controlling for week-of-year fixed effects to partial out seasonal variation. In this framework, the treatment effect is identified by the change in water use relative to the average water use in a given week in the other three years of the sample. Our use of week-of-year fixed effects is likely conservative: part of the impact of any policy change will be absorbed by these fixed effects given the small number of years in our sample. When additional variation is available, we adopt a difference-in-differences design to compare households differentially impacted by 
a given policy. In a difference-in-differences design, the estimated treatment effect is the change in water use between households affected by a treatment at a given time (such as the prohibition on outdoor use water) and similar households that are not. Unless noted otherwise, the standard errors are clustered at the household and sample month level to account for serial correlation and city-level shocks.

\subsection{Rate Changes}

This section estimates the impact of rate changes on household water use. Figure 4 shows the timeline and magnitude of six different rate changes in our sample for marginal, fixed, and average rates separately. Between the beginning and end of this period, marginal rates increased in Fresno. Yet, some rate changes reduced both marginal and fixed rates: notably, in August 2014 the City reversed previous rate increases under political pressure from ratepayers, only to increase rates again the next year after approving a new rate-setting process. This episode emphasizes the degree to which rate changes were salient to households during our sample period.

Because rate changes hit all households in the city simultaneously, the estimates are identified from timeseries variation. Specifically, we compare water use within the same week across the four sample years when different rates are in place. We estimate the following equation:

$$
y_{i t}=\mathrm{f}(\text { Rates })_{i t}+\gamma_{w o y}+\gamma_{i}+X_{t} \theta+\varepsilon_{i t}
$$

where $y_{i t}$ is a function of household $i$ 's average daily water use in week $t$, in gallons, and $\mathrm{f}(\text { Rates })_{c t}$ is a function of either marginal, fixed, or average water rate at week $t$, depending on the specification. Our preferred specification uses the inverse hyperbolic sine of water use and of rates to estimate elasticities because of its robustness to the inclusion of observations with zero water use, $0.96 \%$ of our daily dataset, but we also report estimates using the logarithm. ${ }^{4} \gamma_{\text {woy }}$ and $\gamma_{i}$ are week-of-year, and household fixed effects, $X_{t}$ includes weather and seasonal controls. ${ }^{5}$ Our preferred specification does not include year fixed effects because they would absorb any persistent effects of the policies we study.

Table 1 presents our estimates. Columns 1 and 2, which include year fixed effects, appear to suggest customers are not very sensitive to prices when comparing within-year water use. By contrast, Columns 3 and 4, which do not include year fixed effects, estimate an elasticity of 0.18 with respect to marginal

\footnotetext{
${ }^{4}$ Following Bellemare and Wichman (2020), we multiply the argument of the inverse hyperbolic sine transformations by a large number, 100,000,000, to include observations where the arguments are 0. Algebraically, the multiplicative constant does not affect the regression estimates. Water meter readings of 0 may be due to a week-long vacation, meter malfunctions or water access being shut off to the household on a given day.

${ }^{5}$ Controls include a summer indicator as well as the following indicators constructed at the daily level, and averaged over the days $d$ in each week $t$ : nine indicators for any precipitation, precipitation over 0.2 inches, and precipitation over 0.5 inches on day $d$, day $d-1$, and days $d-2$ to $d-7$, each interacted with the summer indicator, and six indicators for maximum temperature above 95 degrees Fahrenheit and above 100 degrees Fahrenheit on day $d, d-1$ and, days $d-2$ to $d-7$.
} 
prices and 0.43 with respect to average prices. ${ }^{6}$ Columns 5 through 8 , which specify the outcome variable as the $\log$ of average daily water use plus one rather than the inverse hyperbolic sine, find similar results to Columns 1 through 4 . These estimates do not take into account the fact that the city and the state both introduced other policies throughout our sample period; we account for these other factors in our price elasticity estimates in Section 4.

These estimates are consistent with the literature documenting that customers respond more strongly to average rather than marginal prices for water. Specifically, Ito (2013) finds that households in Orange County display a short-run elasticity to average water rates of 0.097 to 0.13 , versus an elasticity with respect to marginal rates of close to zero. ${ }^{7}$ However, unlike Orange County, Fresno does not have increasing block rates; thus we rely only on time-series variation to identify the simultaneous effects of changes in marginal and fixed rates. For this reason, we do not find the coefficient estimates on fixed rates to be credible. Nonetheless, cross-sectional variation in baseline water use combined with time series variation in fixed rates generates variation that allows us to identify the impact of average rates.

\subsection{Reducing the Number of Allowed Outdoor Watering Days}

Next, we evaluate non-price policies, starting with time-of-day and day-of-week restrictions on outdoor water use. These restrictions are ubiquitous throughout California among other drought-prone states and typically target lawn irrigation, the single largest end-use of residential water (Hanak and Davis, 2006). 70\% of Californians were already subject to some restrictions on outdoor water use, even before drought regulations made them mandatory. ${ }^{8}$ Typically these policies restrict outdoor water use to only nights and evenings, when less water is lost to evaporation, and also limit the number of days in a week households can use water outdoors. During our sample period, outdoor water use violations in Fresno were subject to a $\$ 45$ fine. A small team of utility representatives patrolled the city, often at night, targeting customers with a history of high water use during banned hours and issuing fines to customers caught violating water use regulations. First-time violators had the option of having the fine waived if they agreed to a household water audit.

This section exploits a watering schedule change in August 2014 that reduced the number of permitted watering days during summer months from three to two days per week. Ex-ante, it is not clear whether this schedule change will reduce aggregate water use. On the one hand, this policy could update households' beliefs about the frequency with which they need to irrigate their lawns, thus preventing over-irrigation. On the other hand, this policy change does not limit total water use, as households can substitute between

\footnotetext{
${ }^{6}$ We compute elasticities using the following formula derived by Bellemare and Wichman (2020): $\xi_{y x}=\hat{\beta} \cdot \frac{\bar{x} \cdot \sqrt{\bar{y}^{2}+1}}{\bar{y} \cdot \sqrt{\bar{x}^{2}+1}}$ where $\bar{x}$ is the mean of our independent variable and $\bar{y}$ is the mean of our dependent variable.

${ }^{7}$ Ito (2014) documents similar results in the electricity sector.

${ }^{8}$ Authors' calculation based on State Water Resource Control Board data on Conservation Reporting.
} 
hours or days. We start by exploring how water use patterns change with this policy within a day, a week, and even a year. This analysis allows us to document that the policy effects spill over to times when the policy does not bind. We speculate that these spillovers may be due to intertemporal substitution as well as to physical (e.g., swapping out lawns) or mental (e.g., reconsideration of how much water was necessary) capital stock changes. Yet, without experimental or quasi-experimental variation in the policy, we cannot decisively rule out that confounding factors such as secular trends may drive the estimated policy effects. Then, we examine the net impacts of all of these adjustments.

To reduce the load on the stormwater system, houses with odd- and even-numbered addresses are allowed to use water outdoors on different days of the week. During summers prior to August 2014, even-numbered houses were permitted to use water outdoors on Wednesdays, Fridays, and Sundays while odd-numbered houses were permitted to use water outdoors on Tuesdays, Thursdays, and Saturdays. Beginning in August 2014, all customers were also prohibited from using water outdoors on Thursdays and Fridays, reducing the number of days. On Mondays, all households in Fresno are banned from using water outdoors. Table 2 summarizes these summer watering schedule rules before and after this change.

We exploit the fact that even- and odd-numbered households are allowed to water outdoors on different days of the week to estimate the net effect of the schedule restriction in a difference-in-differences design. For example, we can compare the behavior of two neighbors living on the opposite side of the street, at numbers 1 and 2, on different days of the week. Household 1 was never allowed to water on Fridays and can serve as a control group for Household 2, who is newly prohibited from watering on Fridays starting in August 2014, and vice-versa on Thursdays. If we assume that all households comply with the watering schedule, then the difference between even-numbered and odd-numbered household water use on different days would be entirely accounted for by outdoor water use. To the extent that some households do not comply with this regulation, by using differences in water use of households with different watering schedules, we likely underestimate true outdoor water use and consequent savings from this policy restriction. Specifically, we estimate the following equation separately for each hour of the day and different days of the week on the sample of summer months, when outdoor water restrictions are in place: ${ }^{9}$

$$
\begin{aligned}
y_{b n t}= & \beta_{1} \text { BannedDay }_{n t}+\beta_{2} \text { AlwaysPermitted }_{n t} \\
& +\beta_{3} \operatorname{PostBan}_{t}+\beta_{4} \text { BannedDay }_{n t} \times \operatorname{PostBan}_{t}+\beta_{5} \text { AlwaysPermitted }_{n t} \times \operatorname{PostBan}_{t} \\
& +\gamma_{b}+\gamma_{n}+\gamma_{\text {dow }}+\gamma_{w o y}+\gamma_{y r}+\varepsilon_{b n t}
\end{aligned}
$$

\footnotetext{
${ }^{9}$ Due to limitations of computation power, we estimate this equation at the block group - odd/even level, weighting by number of households per block group.
} 
where $y_{b n t}$ is the inverse hyperbolic sine of the average daily water use, in gallons, on week $t$ by the average household in blockgroup $b$ with house number in group $n \in\{$ odd, even $\}$. BannedDay ${ }_{n t}$ is an indicator for the days that become banned in August 2014, that is Thursdays for odd-numbered homes and Fridays for even-numbered homes. AlwaysPermitted ${ }_{n t}$ is an indicator for days when outdoor watering is allowed both before and after August 2014. ${ }^{10}$ The omitted category includes days when outdoor watering is not permitted either before or after August 2014. ${ }^{11}$ PostBan $_{t}$ equals one for weeks after the change in the outdoor watering schedule. Thus, the coefficient $\beta_{3}$ estimates the impact of the ban on water use, $y_{b n t}$, during days when outdoor use was never permitted. The sum of $\beta_{3}+\beta_{4}$ and $\beta_{3}+\beta_{5}$ estimates the effect of the ban on water use on days that become banned and are always permitted, respectively. We control for fixed effects at the block group level, fixed effects for odd- and even-numbered houses, as well as fixed effects for the day of week, week-of-year and year. As such, coefficients in these regressions are identified by the comparison between an even-numbered house that is permitted to water outdoors and an odd-number house in the same Census block group that is not, and vice-versa. Standard errors are clustered at the block group and month level.

We find that intertemporal substitution of water use to days when outdoor watering is still allowed undoes some of the water savings occurring during days when the schedule change binds. Figure 5 presents the hour-by-hour estimates of these regressions on banned, always-permitted, and never-permitted days, respectively. The vertical red lines in the figure delimit daytime hours (9 am to $7 \mathrm{pm}$ ) when outdoor use is never permitted. Panel (a) shows that on the day that becomes banned, water use decreases across all hours of the day by a total of 256 gallons, with $87 \%$ of this decrease (223 gal) occurring at night during hours when irrigation became banned. However, Panel (b) shows that households offset $37 \%$ of these reductions by substituting 94 gallons per week of irrigation from the night that is now banned to the two nights that remain permitted.

All panels in Figure 5 show a puzzling reduction in day-time water use, when outdoor watering is never permitted, either before or after the schedule change. Indeed, summing up changes in water use over all days of the week, Figure 6 shows that despite the substitution of water use from newly banned to permitted times, net water use decreases virtually during all hours, adding up to 333 gallons per week, $10 \%$ of average weekly consumption. Importantly, day-time savings represent $52 \%$ of all savings. This reduction could reflect higher compliance with the watering schedule, perhaps in fear of heightened enforcement, or increased conservation along other dimensions associated with publicity about the schedule change.

To gauge the persistence of the policy effects, Table 3 estimates the total effect of the schedule change by net of both direct and indirect impacts over our entire sample period. Specifically, we estimate the following

\footnotetext{
${ }^{10}$ These days are Tuesdays and Saturdays for odd-numbered homes and Wednesdays and Sundays for even-numbered homes.

${ }^{11}$ These days are Mondays, Wednesdays, Fridays, and Sundays for odd-numbered homes and Mondays, Tuesdays, Thursdays, and Saturdays for even-numbered homes. See Table 2.
} 
equation:

$$
y_{i t}=\beta_{1} I_{t}^{\text {Post-Schedule Change }}+\beta_{2} I_{t}^{\text {Post-Schedule Change }} \times I_{t}^{\text {Summer }}+\gamma_{w o y}+\gamma_{i}+X_{t} \theta+\varepsilon_{i t}
$$

where $y_{i t}$ is the inverse hyperbolic sine of household $i$ 's average daily water use in week $t$ and $I_{t}^{\text {Post-Schedule Change }}$ is an indicator for week $t$ being after the schedule change. $\gamma_{i}$ and $\gamma_{\text {woy }}$ are household, year, and week-of-year fixed effects, and $X_{t}$ are weather controls, including a summer indicator. Column 1 of Table 3 constrains $\beta_{1}$ to be zero, since the outdoor watering schedule did not change in winter months. Column 2 constrains $\beta_{2}$ to be zero, that is it constrains the effect of the schedule change to be constant year-round. Columns 4-6 also include year fixed effects.

Table 3 shows that water use declines by about a third after the schedule change, with little difference across summer and winter months. ${ }^{12}$ One potential explanation for this year-round decrease in water use is that the change in the schedule led to persistent behavior change. ${ }^{13}$ Alternatively, households may have responded to changes in enforcement and City services coinciding with the tightening of the outdoor water regulations. Appendix Figure A.3 shows that enforcement actions and city services such as water audits and timer tutorials are few and far between, suggesting that these factors cannot have a large impact on aggregate water use. Still, without experimental or even quasi-experimental variation in outdoor watering restrictions, we cannot decisively determine whether the decline in winter water consumption is due to persistent behavior changes or reflects confounding factors such as secular trends that also explain the summer reduction.

\subsection{Increasing Public Awareness}

Many environmental programs appeal to moral values to induce behavioral change; yet, it is not clear that they are effective (Egebark and Ekström, 2016). This section examines the extent to which two key policies enacted by the State of California affected public awareness of the drought using Google Trends data: the State of Emergency declaration and the introduction of mandatory water use reductions. We then investigate whether the increased drought awareness during our sample period also led to changes in water use.

First, on January 17, 2014, Governor Jerry Brown declared the whole of California to be in a State of Emergency as a result of the drought. This declaration allowed the State to access federal disaster relief funds and gave the state additional jurisdiction over local water utilities to manage water supply. The governor lifted the State of Emergency after the end of our sample period, on April 7, 2017, for most of the

\footnotetext{
${ }^{12}$ The estimates appear roughly halved when introducing year fixed effects.

${ }^{13} \mathrm{~A}$ wide range of behavior changes may lead to persistent declines in water use, including saving water in daily activities and installing water efficient appliances. To explore the investment channel, we have limited data on city-level take-up of rebates for clothes washers and low-flow toilets, available in Fresno since 2006, as well as rebates for lawn replacements, available since 2015. Appendix Figure A.2 shows no evidence of any discontinuous increase in rebate take-up for clothes washer and toilet rebates. Furthermore, the relatively low take-up of rebates imply that they cannot explain trends in aggregate water use.
} 
state, although some counties remained under it for longer. Second, on April 1, 2015, the State imposed unprecedented mandatory water use reductions on all local water utilities. Requirements included reporting water use monthly to the state as well as $25 \%$ reductions in water use relative to $2013 .{ }^{14}$

Because these policies were one-time announcements that affected all households simultaneously, we exploit time series variation by estimating a regression of water use on a sequence of event-time dummy variables while controlling for secular trends, seasonality, as well as individual fixed effects. In other words, we estimate the following equation:

$$
y_{t}=\sum_{s=-13}^{13} \beta_{s} I_{t}^{\text {Weeks Post-Announcement }}+\gamma_{w o y}+\gamma_{y r}+X_{t} \theta+\varepsilon_{t}
$$

where $y_{t}$ is a measure of drought awareness, $I_{t}^{\text {Weeks Post-Announcement }}$ is an indicator for week $t$ being $s$ weeks before or after the announcement. ${ }^{15} \gamma_{y r}$, and $\gamma_{\text {woy }}$ are year, and week-of-year fixed effects, and $X_{t}$ are weather controls.

First, we examine the effect of these policies on drought awareness. We use Google Trends to construct a weekly index of the number of searches within Fresno containing the word "Drought". Figure 7 plots the coefficients from equation (4) where $y_{t}$ is the drought awareness index. ${ }^{16}$ Both policy announcements, and especially the State of Emergency announcement, appear to increase awareness of the drought as measured by our index. By contrast, the change in the outdoor watering schedule does not appear to increase drought awareness.

Next, we ask whether this increase in awareness translates to a decrease in water use. Figure 8 plots this measure of drought interest against water use after removing seasonal patterns. Average water use and interest in the drought move in opposite directions, with a correlation coefficient of -0.498 . To further explore this pattern, we estimate the following event-study equation:

$$
y_{i t}=\sum_{s=-13}^{13} \beta_{s} I_{t}^{\text {Weeks Post-Announcement }}+\gamma_{w o y}+\gamma_{y r}+\gamma_{i}+X_{t} \theta+\varepsilon_{i t}
$$

where $y_{i t}$ is the inverse hyperbolic sine of household $i$ 's average daily water use in week $t$ and $I_{t}^{\text {Weeks Post-Announcement }}$ is an indicator for week $t$ being $s$ weeks before or after the announcement. ${ }^{17} \gamma_{i}, \gamma_{y r}$, and $\gamma_{w o y}$ are household, year, and week-of-year fixed effects, and $X_{t}$ are weather controls.

\footnotetext{
${ }^{14}$ In addition, this regulation instituted a temporary, state-wide consumer rebate program to replace old appliances with water- and energy-efficient models; required campuses, golf courses, cemeteries, and other properties with large green spaces to make significant cuts in water use; prohibited new home developments from irrigating with potable water; prohibited irrigation of street medians; prohibited the serving of tap water in restaurants unless asked for by customers; and prohibited irrigation in days following rainfall.

${ }^{15}$ Indicators for weeks -13 and 13 include also weeks before and after the window, respectively.

${ }^{16}$ Because the drought awareness index is constructed at the city level, this specification does not include household fixed effects.

${ }^{17}$ Indicators for weeks -13 and 13 include also weeks before and after the window, respectively.
} 
Figure 9 plots the coefficients from equation (5), suggesting that both announcements are associated with declines in water use. We interpret these results as indicating that drought awareness is negatively correlated with water consumption and explore the robustness of this finding to controlling for the other policies that were in force in this period in the next section.

\section{The Policies' Impact on Total Water Conservation}

In this section, we use a unified linear regression framework to estimate the impact of the policies discussed independently in Section 3. This unified framework enables us to account for the simultaneous introduction of different policies and to estimate the contribution of each policy to total water conservation. Specifically, we estimate the following equation:

$$
\begin{aligned}
y_{i t}= & \beta_{1} \operatorname{IHS}(\text { Rate })_{i t} \\
& +\beta_{2} I_{t}^{\text {PostScheduleChange }} \times I_{t}^{\text {Summer }} \\
& +\beta_{3} \text { Drought Interest }_{t} \\
& +\gamma_{i}+\gamma_{\text {woy }}+f\left(\text { Weather }_{t}\right)+\varepsilon_{i t}
\end{aligned}
$$

where $y_{i t}$ is the inverse hyperbolic sine (IHS) of household $i$ 's average daily use during week $t$, IHS(Rate) ${ }_{i t}$

is alternatively the IHS of the average rate or the IHS of marginal and fixed rates, $I_{t}^{\text {PostScheduleChange }}$ is an indicator that equals 1 after the schedule change, and Drought Interest ${ }_{t}$ is our measure of Google searches related to the drought. We report versions of this specification that do and do not include year fixed effects, where the latter are more susceptible to confounding factors but enable estimation of long-run effects (instead of limiting identification to the year of implementation). Table 4 presents estimates from this regression with marginal and fixed rates in Columns 1-2 and average rates in Columns 3-4.

When simultaneously estimating the impact of the policies, these regressions estimate similar policy effects to those identified separately in Section 3. First, Table 4 estimates a price elasticity of water demand of 0.16 with respect to marginal rates, and of 0.39 with respect to average rates, both very similar to the estimates in Table 1. It is also apparent that the price elasticities are smaller in the specifications that include year fixed effects, but we do not emphasize these specifications because they do not take advantage of all of the identifying variation. Second, we find substantial long-term impacts of the schedule change during the summer, on the order of 29 to $33 \%$, similar to those estimated in Table 3. It is noteworthy that the winter effect remains even when conditioning on the price and drought variables (see Appendix Table 
A.2). Finally, we estimate no effect of drought awareness on water conservation after controlling for the other policies. This finding suggests that awareness has no additional explanatory power after accounting for the impact of the other policies. ${ }^{18}$

Next, we decompose the total water savings we observe in Fresno between 2013 and 2016 into components attributable to each of the policies analyzed in Table 4. First, we calculate 'Actual Changes' in water use each year relative to a baseline before any policy changes in the first half of 2013 . Then, we compute 'PolicyInduced Changes' by predicting water use each year based on the coefficients estimating policy impacts in each column of Table 4. Specifically, we compute the following equation for each year $t \in 2014-2016$ :

$$
\text { Policy Induced Changes }=\sum_{i=1}^{3} \hat{\beta}_{i}\left(\text { Policy }_{i t}-\text { Policy }_{i 0}\right)
$$

Table 5 reports the results of this exercise year-by-year using estimates including marginal and fixed rates (Columns 1-3) and average rates (Columns 4-6). Specifically, rate changes appear to explain 40-44\% of the water savings in 2016 compared to 2013, while the schedule change explains $45-51 \%$ of those savings, and drought interest explains at most $2 \%$ of the savings, depending on which measure of rates we use.

We caveat this analysis by noting that the results from this exercise are sensitive to how we interpret the effects of the schedule change in the winter. When we include the effects of this policy in all months of the year as opposed to only the summer months when the schedule change is binding, Appendix Table A.4 shows that our analysis over-predicts water savings. Without data from control cities, or even better from a randomized trial, we cannot say whether the policy effects we estimate when the policy was not in effect are due to persistent behavior changes such as lawn replacements or to confounding factors such as secular trends that might also explain the effect in the summer.

\section{Conclusion}

Resource conservation is one of the common challenges that societies face. Climate change is likely to make crises, such as droughts, more common, putting policymakers under more frequent pressure to adopt conservation policies. By trying to disentangle the impact of different policies on water conservation, this paper aims to provide a toolkit for policymakers to reduce resource use. To do so, we take different approaches to assessing the impacts of different policies depending on the identifying variation available in the data.

The paper's primary contribution is to simultaneously estimate the impact of aggregate policies such as outdoor watering restrictions, rate changes, and policies aimed at increasing drought awareness. First, we

\footnotetext{
${ }^{18}$ Appendix Table A.3 shows that our estimates are robust to using logarithm transformations of the outcome and the rate variables instead of the inverse hyperbolic sine transformation.
} 
find that increasing water rates explain 40-44\% of the water conservation experienced in Fresno between 2013 and 2016. Our analysis abstracts from political economy considerations that marginal rate increases can be viewed as punitive, disproportionally affect low-income customers (Wichman, Taylor, and Haefen, 2016), and divorce revenues from the cost structure of utilities, thus increasing risk. Second, we find that tightening summer outdoor watering restrictions decreased summer water use despite intertemporal substitution to permitted times. However, we also find a decline in winter use that complicates the interpretation of these results. Indeed, using only time-series variation in Fresno, we cannot decisively conclude whether the policy effects we estimate when the policy was not in effect are due to persistent behavior changes or to confounding factors such as secular trends that might also explain the effect in the summer. Moreover, we cannot quantify the welfare impacts of the schedule change as we lack data on the disutility it imposes on households. Third, we do not find evidence that increased drought awareness due to state-level announcements leads to longterm water conservation. However, identifying the impact of conservation and media campaigns remains an open and crucial question for demand management policy going forward.

We also have data on take-up of rebates for water-efficient appliances and conservation services offered by the City through programs that did not change over our sample period. In analysis not reported in the paper, we find that installing water-efficient toilets and drought-resistant lawns reduces household water use, as does receiving timer tutorials and water use audits. However, the aggregate impacts of these rebates and customer services are negligible due to low take-up rates. Most water utilities in California offer rebates for water-efficient appliances on top of rebates offered by the State through the 'Save Our Water' program, despite mixed evidence on the effectiveness of resource-efficient appliances at reducing use due to rebound effects (Bennear, Lee, and Taylor, 2013; Lee, Tansel, and Balbin, 2011; Lee, Tansel, and Balbin, 2013; Davis, 2008; Gillingham et al., 2013). Anecdotally, most households redeem both city- and state-offered rebates, meaning rebates could cover the total cost of a toilet and up to $40 \%$ of the cost of a new washer. Similarly, virtually all utilities in California enforce outdoor water use restrictions and offer services such as water audits and timer tutorials. Thus, we believe that further research is warranted to study the scalability and cost-effectiveness of these policies, given that there likely are many infra-marginal takers.

Understanding what works in managing resource use during crises is paramount to navigate the challenges posed by climate change. Answering this question requires sorting out the impacts of policies that are often enacted simultaneously. Importantly, this simultaneity also raises questions of the complementarity or substitutability of these policies, which will affect the external validity of our findings. This paper provides novel associational evidence, but decisive evidence of the impacts of multiple policies and their interactions requires experimental or valid quasi-experimental variation in them. We are especially optimistic about opportunities to implement randomized control trials (Browne et al., 2020). 


\section{References}

Allcott, Hunt (2011). "Social norms and energy conservation". In: Journal of public Economics 95.9-10, pp. 1082-1095.

- (2016). "Paternalism and energy efficiency: an overview". In: Annual Review of Economics 8, pp. 145176.

Allcott, Hunt and Todd Rogers (2014). "The short-run and long-run effects of behavioral interventions: Experimental evidence from energy conservation". In: American Economic Review 104.10, pp. 3003-37.

Asensio, Omar I. and Magali A. Delmas (2015). "Nonprice incentives and energy conservation". In: Proceedings of the National Academy of Sciences 112.6, E510-E515. ISSN: 0027-8424.

Baerenklau, Kenneth A., Kurt A. Schwabe, and Ariel Dinar (2014). "The Residential Water Demand Effect of Increasing Block Rate Water Budgets". In: Land Economics 90.4, pp. 683-699.

Baumol, William J. (1988). The theory of environmental policy. Cambridge university press.

Bellemare, Marc F. and Casey J. Wichman (2020). "Elasticities and the Inverse Hyperbolic Sine Transformation". In: Oxford Bulletin of Economics and Statistics 82 (1), pp. 50-61.

Bennear, Lori S., Jonathan M. Lee, and Laura O. Taylor (2013). "Municipal Rebate Programs for Environmental Retrofits: An Evaluation of Additionality and Cost-Effectiveness". In: Journal of Policy Analysis and Management 32.2, pp. 350-372.

Bhanot, Syon P. (2018). "Isolating the Effect of Injunctive Norms on Conservation Behavior: New Evidence from a Field Experiment in California". In: Organizational Behavior and Human Decision Processes.

Brent, Daniel A., Joseph H. Cook, and Skylar Olsen (2015). "Social Comparisons, Household Water Use, and Participation in Utility Conservation Programs: Evidence from Three Randomized Trials". In: Journal of the Association of Environmental and Resource Economists 2.4, pp. 597-627.

Browne, Oliver R., Ludovica Gazze, Michael Greenstone, and Olga Rostapshova (2020). "Enforcement and Deterrence with Certain Detection: An Experiment in Water Conservation Policy". Working Paper.

Castledine, A., K. Moeltner, M.K. Price, and S. Stoddard (Nov. 2014). "Free to Choose: Promoting Conservation by Relaxing Outdoor Watering Restrictions". In: Journal of Economic Behavior E Organization 107, pp. 324-343.

Davis, Lucas W. (2008). "Durable Goods and Residential Demand for Energy and Water: Evidence from a Field Trial”. In: RAND Journal of Economics 39.2, pp. 530-546.

Egebark, Johan and Mathias Ekström (2016). "Can Indifference Make the World Greener?" In: Journal of Environmental Economics and Management 76, pp. 1-13. 
Ferraro, Paul J., Juan Jose Miranda, and Michael K. Price (2011). "The Persistence of Treatment Effects with Norm-Based Policy Instruments: Evidence from a Randomized Environmental Policy Experiment". In: American Economic Review. Vol. 101. 3, pp. 318-322.

Ferraro, Paul J. and Michael K. Price (2013). "Using Nonpecuniary Strategies to Influence Behavior: Evidence from a Large-Scale Field Experiment". In: Review of Economics and Statistics 95.1, pp. 64-73.

Gillingham, Kenneth, Matthew J Kotchen, David S Rapson, and Gernot Wagner (2013). "Energy policy: The rebound effect is overplayed". In: Nature 493.7433, p. 475.

Grafton, R. Quentin and Michael B. Ward (2008). "Prices Versus Rationing: Marshallian Surplus and Mandatory Water Restrictions". In: Economic Record 84, S57-S65.

Griffin, Daniel and Kevin J. Anchukaitis (2014). "How Unusual is the 2012 - 2014 California Drought?" In: Geophysical Research Letters 41, pp. 9017-9023.

Halich, Greg and Kurt Stephenson (2009). "Effectiveness of Residential Water-Use Restrictions Under Varying Levels of Municipal Effort". In: Land Economics 85.4, pp. 614-626.

Hanak, Ellen and Matthew Davis (2006). "Lawns and Water Demand in California". In: California Economic Policy, 2.2.

Hensher, David, Nina Shore, and Kenneth Train (2006). "Water Supply Security and Willingness to Pay to Avoid Drought Restrictions". In: Economic Record 82.256, pp. 56-66.

Ito, Koichiro (2013). "How Do Consumers Respond to Nonlinear Pricing? Evidence from Household Water Demand". Working Paper.

- (2014). "Do Consumers Respond to Marginal or Average Price? Evidence from Nonlinear Electricity Pricing”. In: American Economic Review 104.2, pp. 537-563. ISSN: 00028282.

Ito, Koichiro, Takanori Ida, and Makoto Tanaka (Feb. 2018). "Moral Suasion and Economic Incentives: Field Experimental Evidence from Energy Demand". In: American Economic Journal: Economic Policy 10.1, pp. 240-67.

Jessoe, Katrina, Gabriel Lade, Frank Loge, and Edward Spang (2018). "Spillovers from Behavioral Interventions: Experimental Evidence from Water \& Energy Use".

Jessoe, Katrina and David Rapson (Apr. 2014). "Knowledge Is (Less) Power: Experimental Evidence from Residential Energy Use". In: American Economic Review 104.4, pp. 1417-38.

Kenney, Douglas S., Roberta A. Klein, and Martyn P. Clark (2004). "Use and Effectiveness of Municipal Water Restrictions During Drought in Colorado". In: Journal of the American Water Resources Association 40.1, pp. $77-87$.

Klaiber, H Allen, V Kerry Smith, Michael Kaminsky, and Aaron Strong (2014). "Measuring Price Elasticities for Residential Water Demand with Limited Information". In: Land Economics 90.1, pp. 100-113. 
Labandeira, Xavier, José M. Labeaga, and Xiral López-Otero (2017). "A Meta-Analysis on the Price Elasticity of Energy Demand". In: Energy Policy 102, pp. 549-568. ISSN: 0301-4215.

Lee, Mengshan, Berrin Tansel, and Maribel Balbin (2011). "Influence of Residential Water Use Efficiency Measures on Household Water Demand: A Four Year Longitudinal Study". In: Resources, Conservation and Recycling 56.1, pp. 1-6.

- (2013). "Urban Sustainability Incentives for Residential Water Conservation: Adoption of Multiple High Efficiency Appliances". In: Water Resources Management 27.7, pp. 2531-2540.

Mansur, Erin T. and Sheila M. Olmstead (2012). "The Value of Scarce Water: Measuring the Inefficiency of Municipal Regulations". In: Journal of Urban Economics 71.3, pp. 332-346.

Michelsen, An M., J. Thomas. McGuckin, and Donna Stumpf (1999). "Nonprice Water Conservation Programs as a Demand Management Tool". In: Journal of the American Water Resources Association 35.3, pp. 593-602.

Nataraj, Shanthi and W. Michael Hanemann (2011). "Does Marginal Price Matter? A Regression Discontinuity Approach to Estimating Water Demand". In: Journal of Environmental Economics and Management 61.2, pp. $198-212$.

Olmstead, Sheila M. (2009). "Reduced-Form Versus Structural Models of Water Demand Under Nonlinear Prices". In: Journal of Business \&3 Economic Statistics 27.1, pp. 84-94.

Olmstead, Sheila M., W. Michael Hanemann, and Robert N. Stavins (2007). "Water Demand Under Alternative Price Structures". In: Journal of Environmental Economics and Management 54.2, pp. 181198.

Olmstead, Sheila M. and Robert N. Stavins (2009). "Comparing Price and Nonprice Approaches to Urban Water Conservation". In: Water Resources Research 45.4.

Pratt, Bryan (2019). "A Fine Is More Than a Price: Evidence from Drought Restrictions". Working Paper.

Renwick, Mary E. and Richard D. Green (2000). "Do residential water demand side management policies measure up? An analysis of eight California water agencies". In: Journal of Environmental Economics and Management 40.1, pp. 37-55.

Syme, Geoffrey J, Blair E Nancarrow, and Clive Seligman (2000). "The Evaluation of Information Campaigns to Promote Voluntary Household Water Conservation". In: Evaluation Review 24.6, pp. 539-578.

Viard, V Brian and Shihe Fu (2015). "The effect of Beijing's driving restrictions on pollution and economic activity". In: Journal of Public Economics 125, pp. 98-115.

Wichman, Casey J. (2014). "Perceived Price in Residential Water Demand: Evidence from a Natural Experiment". In: Journal of Economic Behavior 83 Organization 107, pp. 308-323. 
Wichman, Casey J., Laura O. Taylor, and Roger H. von Haefen (2016). "Conservation Policies: Who Responds to Price and Who Responds to Prescription?" In: Journal of Environmental Economics and Management 79.

Zhang, Wei, C-Y Cynthia Lin Lawell, and Victoria I Umanskaya (2017). "The Effects of License Plate-Based Driving Restrictions on Air Quality: Theory and Empirical Evidence". In: Journal of Environmental Economics and Management 82, pp. 181-220. 


\section{Figures}

Figure 1: California Drought Severity

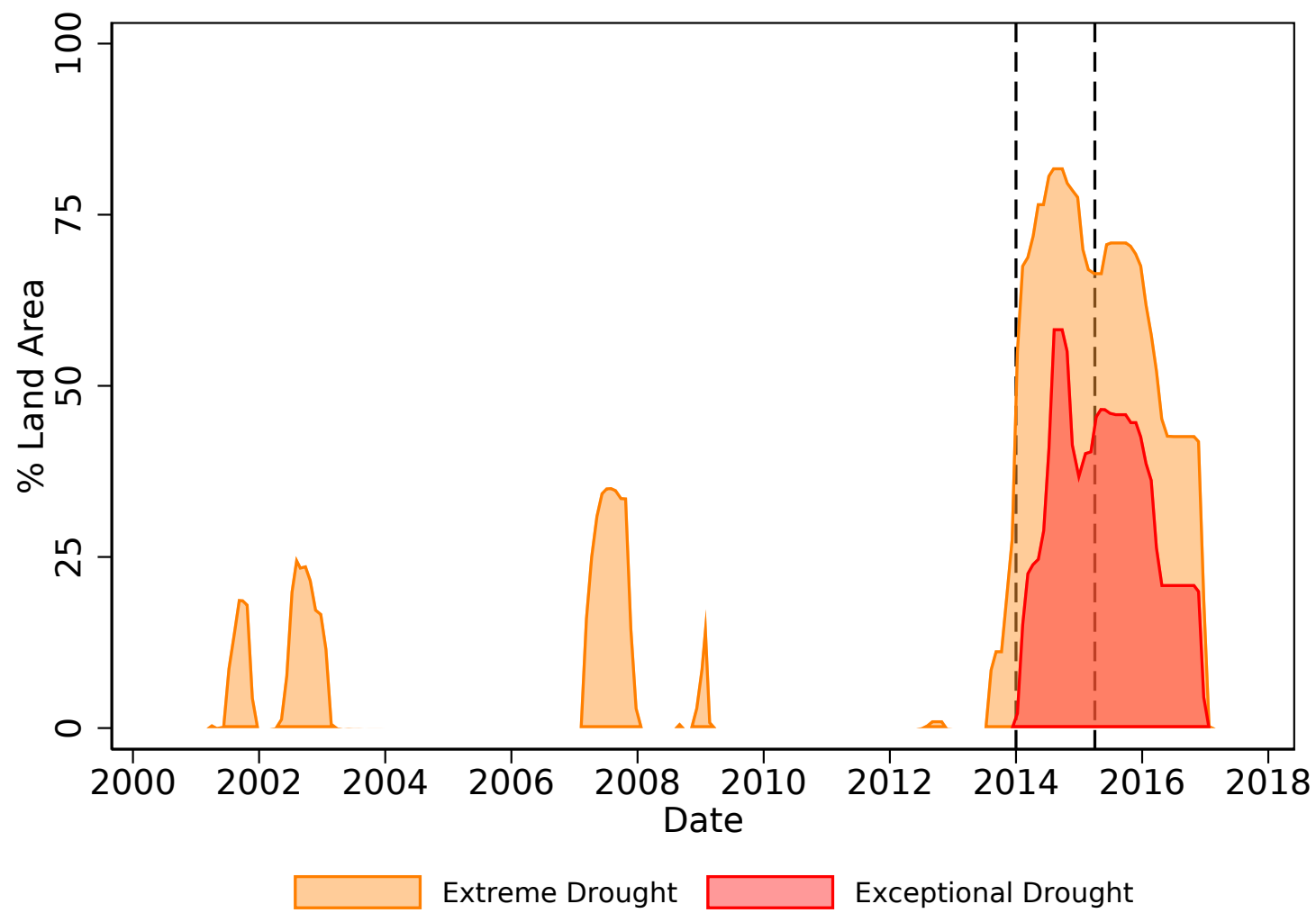

Notes: Using data from the United States Drought Monitor, this figure shows the percent of California in moderate to severe drought from January 2000 to February 2018. 
Figure 2: Per Capita Daily Residential Water Use in California in 2013

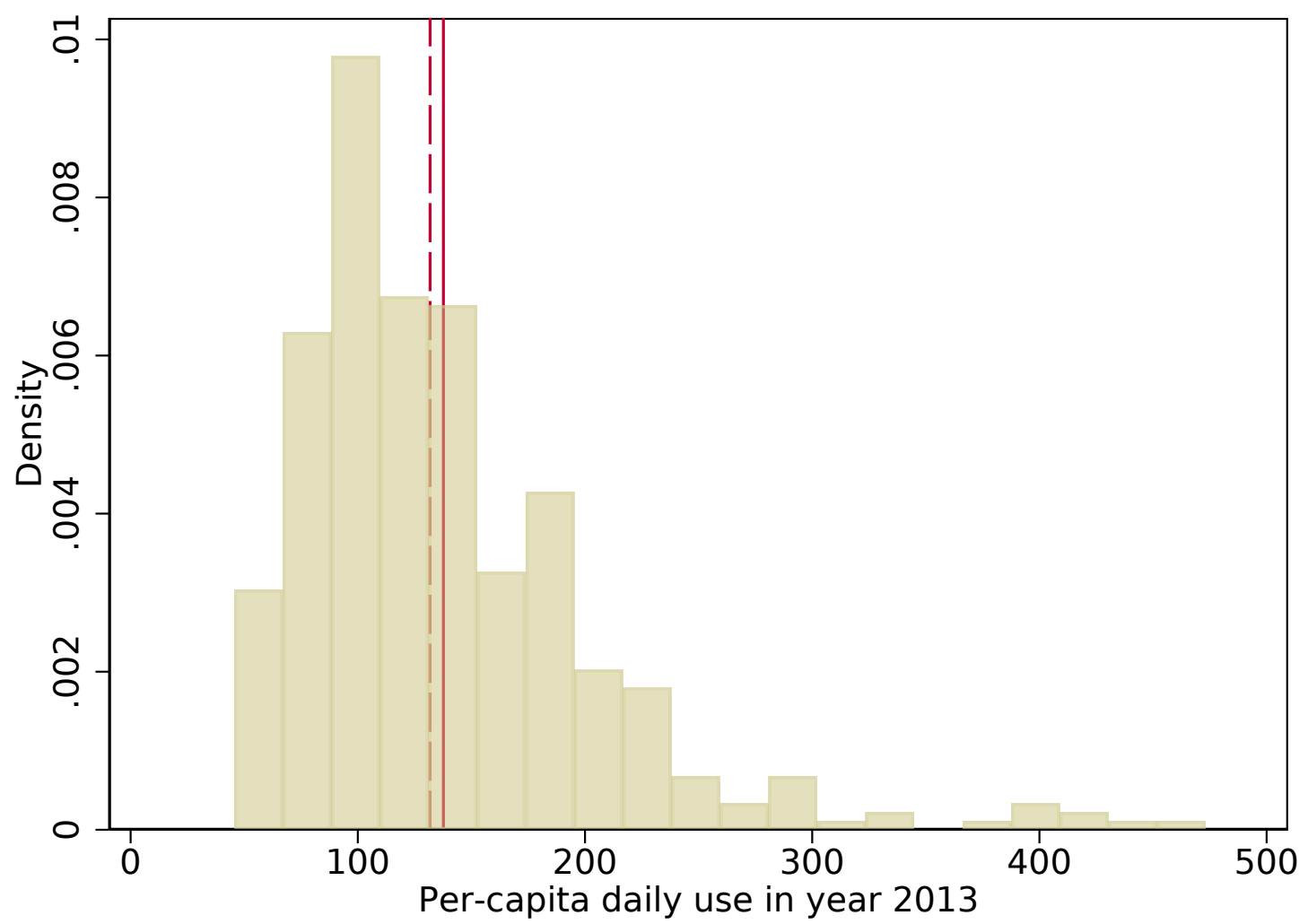

Notes: In this graph, the dashed line represents the average for Fresno (132 gal/day) whereas the solid line represents the average for all utilities in California (138 gal/day). Source: California State Water Resources Control Board, accessed at https://www.waterboards.ca.gov/water_issues/programs/conservation_ portal/conservation_reporting.html on April 2, 2019. These data include all residential households, whereas the analysis in this paper only includes single-family households. 
Figure 3: Average Daily Water Use and Policy Changes in Fresno, 2013-2016

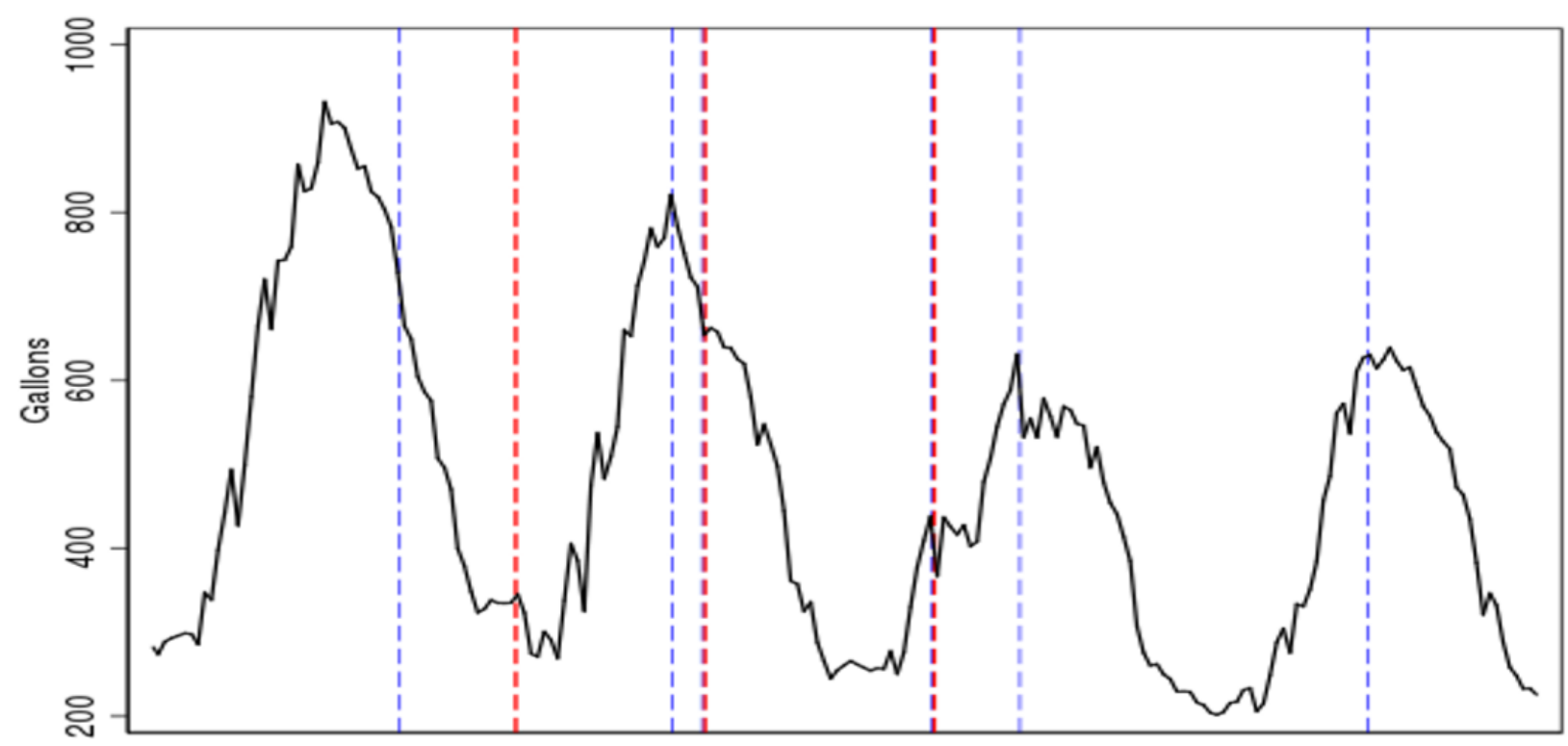

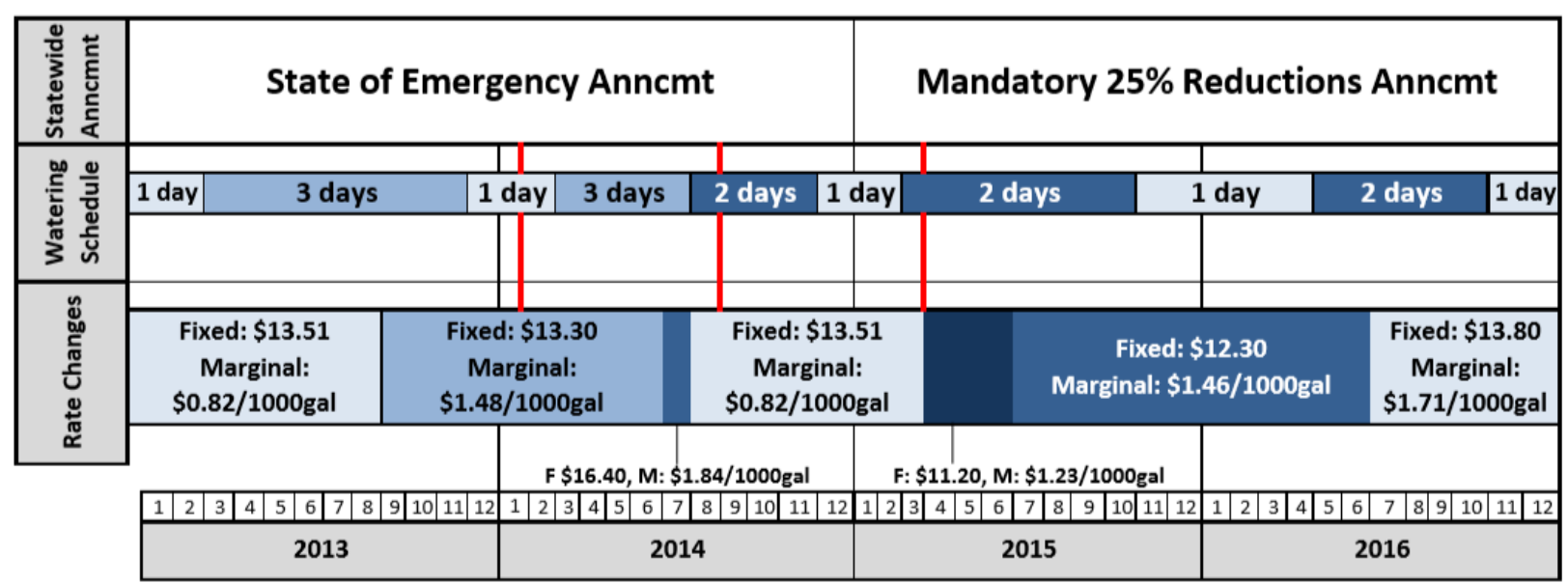

Notes: The top panel of this figure shows average daily water use. The bottom panel shows all of the policy changes we analyze. Red lines in the figure correspond to each statewide announcement was introduced. Blue lines correspond to each rate change. 
Figure 4: Rate Changes between 2013 and 2016
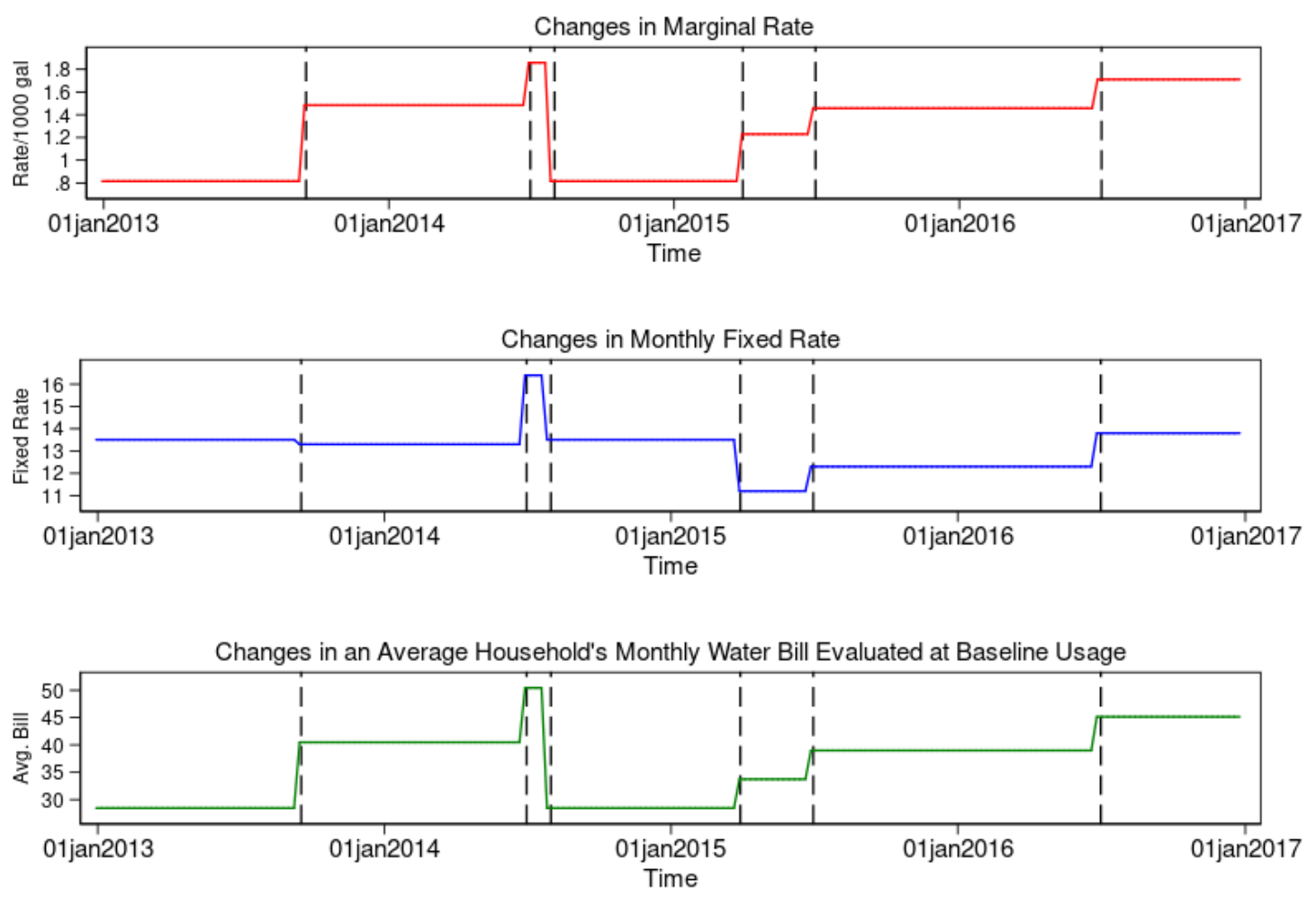

Notes: The top, middle and bottom figures respectively show changes in the marginal, fixed and average rates charged throughout the sample period. Fixed rates shown only for 1" sized water meter. Average rates are calculated based on the households monthly water use at the beginning of the sample period. 
Figure 5: Water Use After Outdoor Schedule Change, by Hour of Day and Day Type

(a) Banned Watering Day

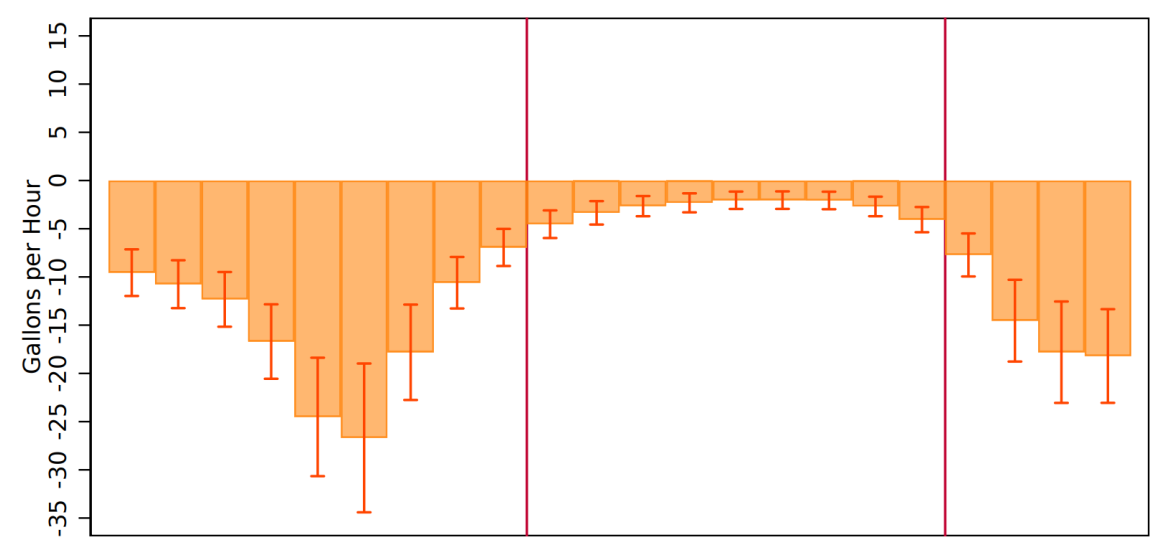

(b) Always Permitted Watering Day

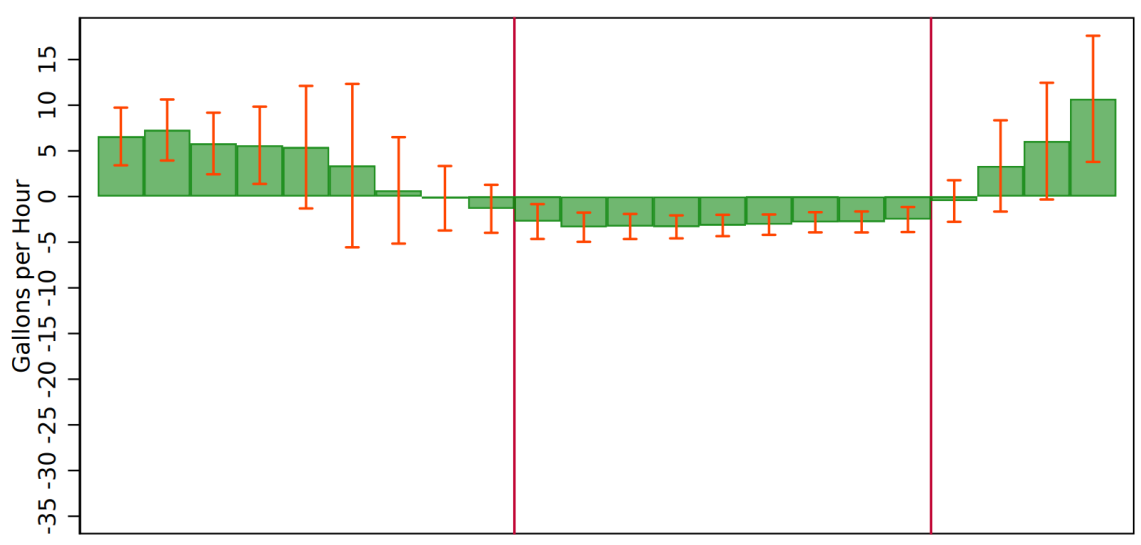

(c) Never Permitted Watering Day

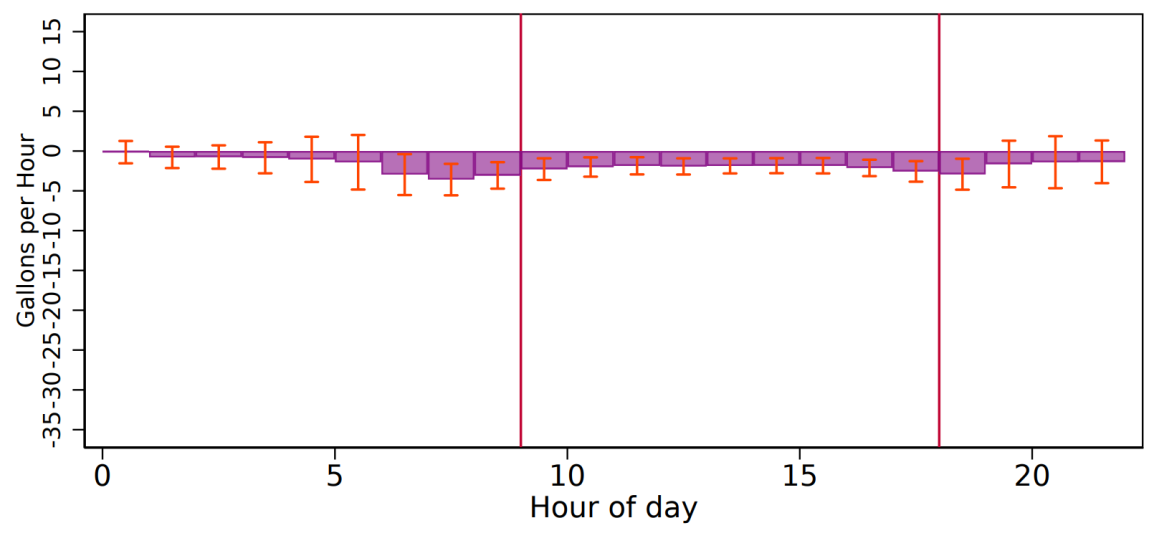

Notes: This figure shows coefficients from hour-by-hour regressions of water use on indicator variables for whether outdoor water-use for a household on that day of the week was either; banned after the policy change (Panel a), always-permitted (Panel b), or never-permitted (Panel c). Each regression includes indicators for the day of the week, an indicator for post schedule change, and interactions between indicators for "post schedule change", "banned day" and "always permitted day." The regression also controls for whether households live in even-numbered homes, census block group fixed effects, and fixed effects for the day of week, week of year and year. Each regression is weighed by number of households in the census block group. Standard errors are two-way clustered at census block group and sample-month levels. Red lines delimit daytime hours (9 am to $7 \mathrm{pm}$ ) when outdoor use is never permitted. 
Figure 6: Average Effect of Schedule change on Use, by Hour

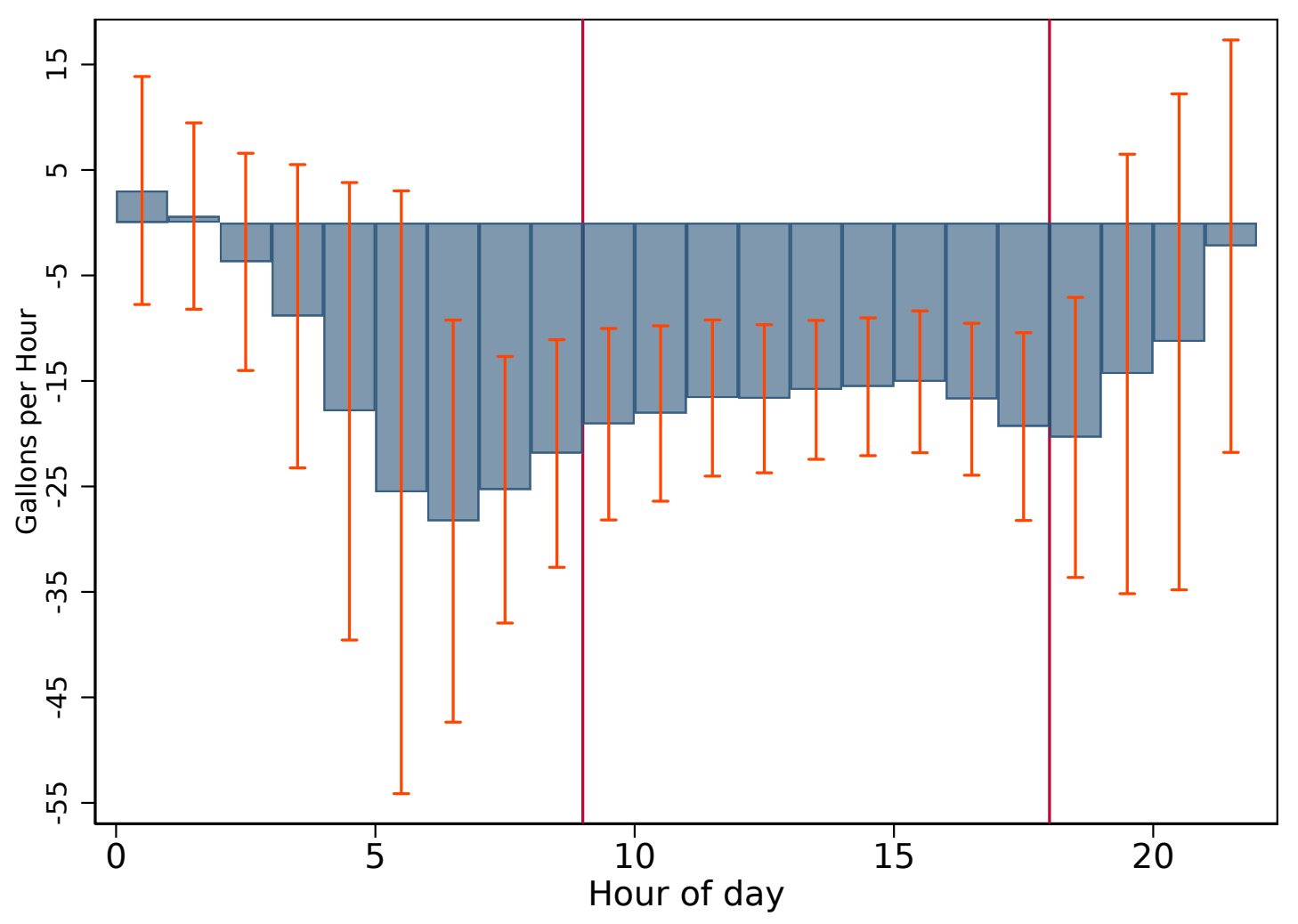

Notes: This figure calculates the average hour-by-hour impact of schedule change on weekly water use. The averages are calculated from the regression coefficients in Figure 5. The estimates are weighted given that after the schedule change, each week has one day that became banned, two days that were always-permitted, and four days that were never-permitted. The red lines delimit daytime hours (9 am to 7 $\mathrm{pm})$ when outdoor use is never permitted. 
Figure 7: Event-time Estimates — the Impact of Announcements on Drought Interest

(a) Effect of a State of Emergency Announcement

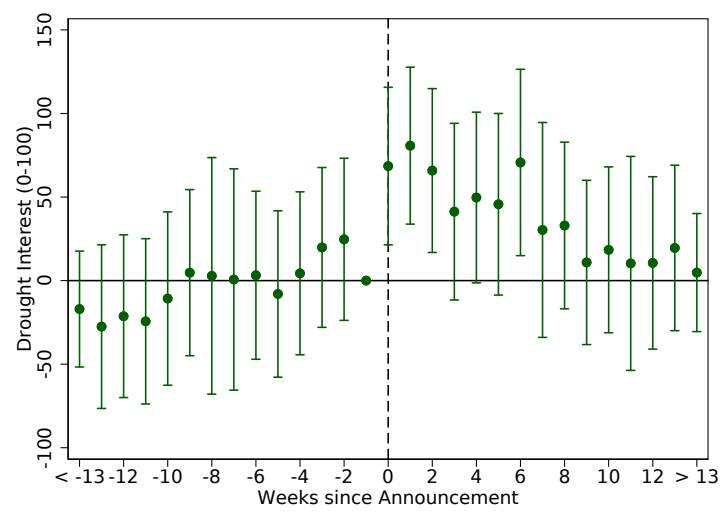

(b) Effect of California Mandated Reductions

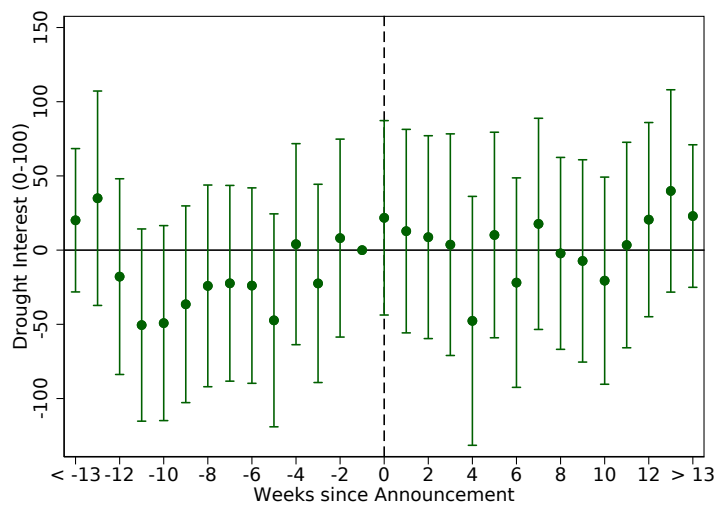

(c) Effect of Outdoor Water Use Schedule Change

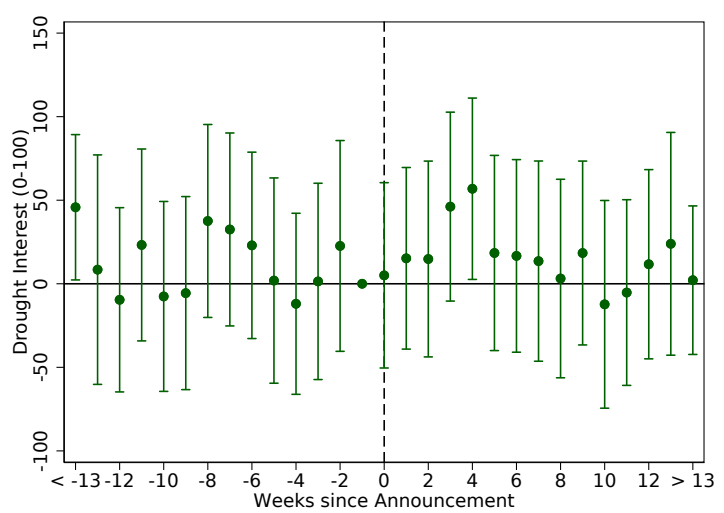

Notes: This figure shows week-by-week event-time coefficients from regressing our drought interest measure obtained from Google searches on indicators for each week relative to the emergency state announcement (Panel a), the state-mandated reductions (Panel b), and the schedule change (Panel c). Each regression includes weather controls, a control for whether summer watering schedule is in place, household fixed effects, and fixed effects in year and week of the year. Standard errors are two-way clustered at household and sample-month levels. Graphs show coefficient estimates and the $95 \%$ confidence intervals. 
Figure 8: Drought Interest and Water Use over Time

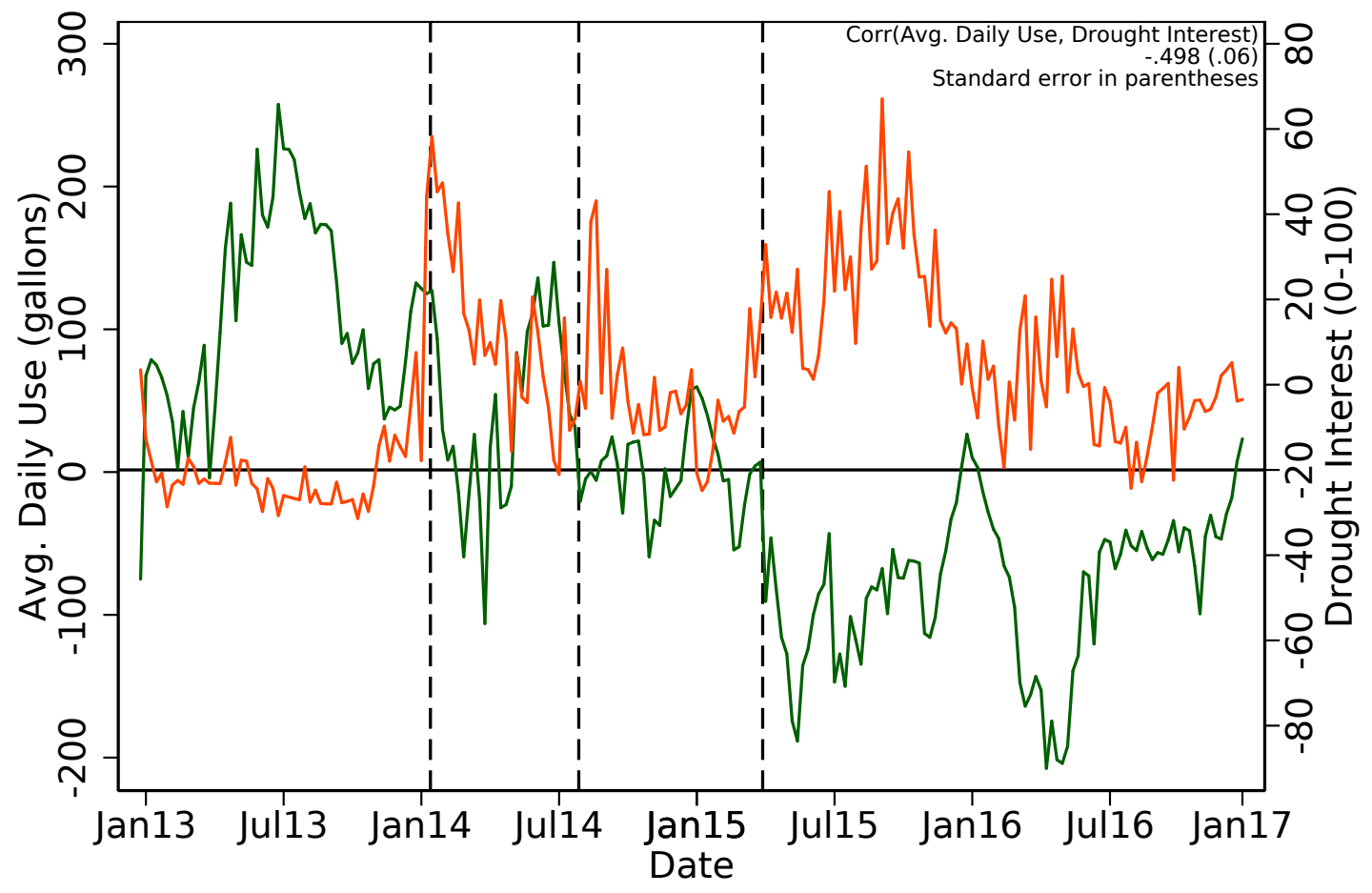

Avg. Daily Use (gallons)

Drought Interest (0-100)

Notes: This figure plots a weekly times series of de-seasoned average daily water use and drought interest. The drought interest measure is computed from Google searches for the word "drought". Vertical lines indicate dates of the State of Emergency announcement, the outdoor watering schedule change, and the mandated restrictions. 
Figure 9: Event-time Estimates - the Impact of State-Wide Conservation Announcements on Water Use

(a) Effect of State of Emergency Announcement

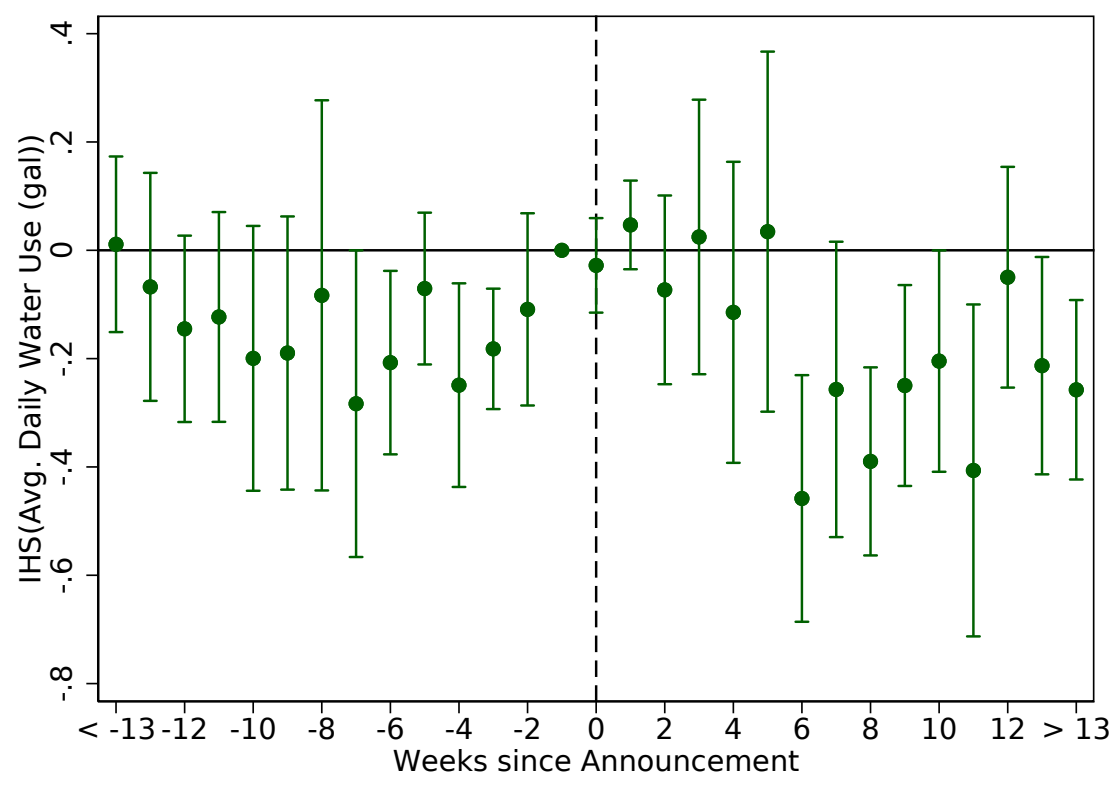

(b) Effect of California Mandated Reductions

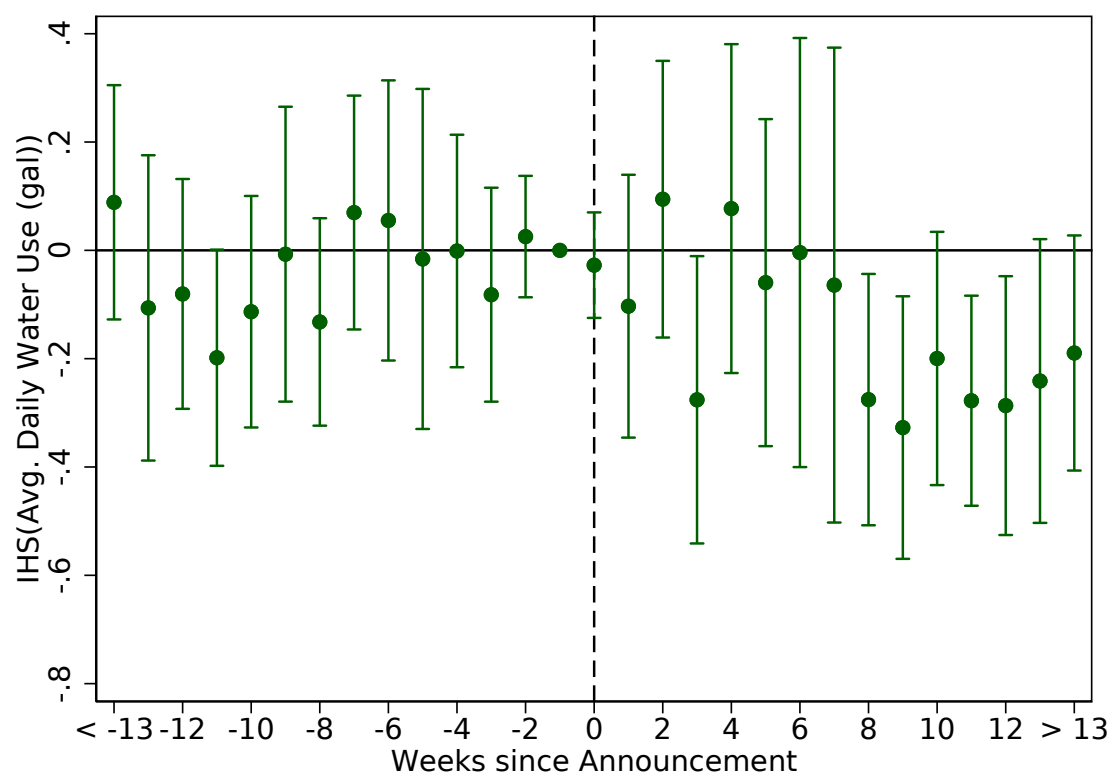

Notes: This figure shows week-by-week event-time coefficients from regressing the inverse hyperbolic sine of average daily water use on indicators for each week relative to Jerry Brown's January 17, 2014 announcement that the drought had placed California in a State of Emergency (Panel a) and California's announcement on Apr 1, 2015 that all municipalities would be collectively required to reduce water use by $25 \%$ (Panel b). Each event-time estimate includes weather controls, a control for whether summer watering schedule is in place, household fixed effects, and fixed effects in year and week of the year. Standard errors are two-way clustered at household and sample-month levels. Graphs show coefficient estimates and the $95 \%$ confidence intervals. 


\section{Tables}

Table 1: Elasticity of Average Daily Use

\begin{tabular}{|c|c|c|c|c|c|c|c|c|}
\hline \multirow[t]{2}{*}{ Dependent Variable } & \multicolumn{4}{|c|}{ IHS of Average Daily Use (gallons) } & \multicolumn{4}{|c|}{ Log of (1+Average Daily Use(gal)) } \\
\hline & (1) & $(2)$ & (3) & (4) & (5) & (6) & (7) & (8) \\
\hline \multicolumn{9}{|c|}{ Panel A: Regression Coefficients } \\
\hline Fixed Rate & $\begin{array}{c}0.945^{* * *} \\
(0.189)\end{array}$ & & $\begin{array}{c}1.379^{* * *} \\
(0.157)\end{array}$ & & $\begin{array}{c}0.761^{* * *} \\
(0.137)\end{array}$ & & $\begin{array}{c}1.180^{* * *} \\
(0.131)\end{array}$ & \\
\hline Marginal Rate per Gallon & $\begin{array}{c}0.043 \\
(0.037)\end{array}$ & & $\begin{array}{c}-0.185^{* * *} \\
(0.067)\end{array}$ & & $\begin{array}{c}0.033 \\
(0.031)\end{array}$ & & $\begin{array}{c}-0.191^{* * *} \\
(0.060)\end{array}$ & \\
\hline Average Rate per Gallon & & $\begin{array}{l}-0.108 \\
(0.107)\end{array}$ & & $\begin{array}{c}-0.425^{* * *} \\
(0.150)\end{array}$ & & $\begin{array}{l}-0.037 \\
(0.076)\end{array}$ & & $\begin{array}{c}-0.373^{* * *} \\
(0.124)\end{array}$ \\
\hline
\end{tabular}

Panel B: Implied Elasticities

Marginal Rate per Gallon

0.04

$-0.18$

0.03

$-0.19$

Average Rate per Gallon

$-0.11$

$-0.43$

$-0.04$

$-0.37$

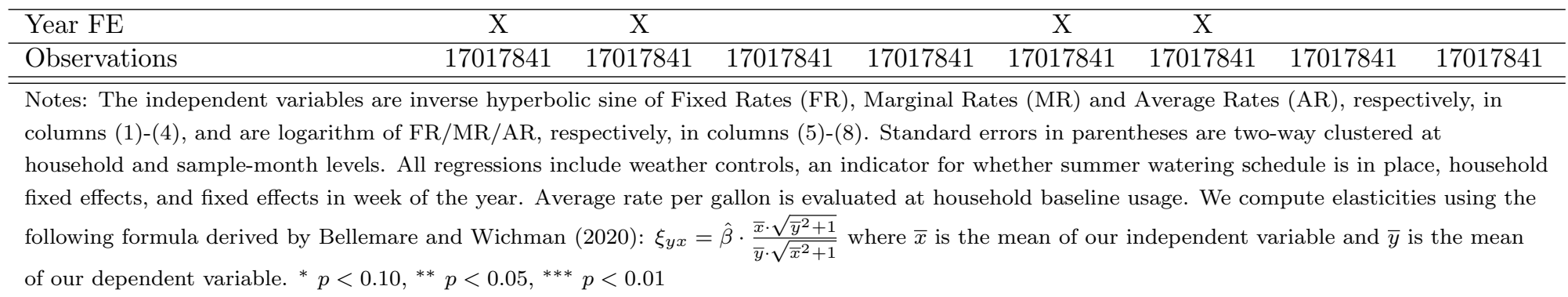


Table 2: Outdoor Water Use Schedule Before and After August 2014

\begin{tabular}{|c|c|c|c|c|c|c|c|c|c|}
\hline \multirow{3}{*}{ Day } & \multirow{3}{*}{ Type of Day } & \multicolumn{4}{|c|}{ Odd } & \multicolumn{4}{|c|}{ Even } \\
\hline & & \multicolumn{2}{|c|}{ Summer } & \multicolumn{2}{|c|}{ Winter } & \multicolumn{2}{|c|}{ Summer } & \multicolumn{2}{|c|}{ Winter } \\
\hline & & Before & After & Before & After & Before & After & Before & After \\
\hline Monday & Always Banned & & & & & . & . & . & ${ }^{\circ}$ \\
\hline Tuesday & Always Allowed Summer Day & $\mathrm{X}$ & $\mathrm{X}$ & & . & . & . & . & . \\
\hline Wednesday & Always Allowed Summer Day & & & & . & $\mathrm{X}$ & $\mathrm{X}$ & . & . \\
\hline Thursday & Banned after 08/01/2014 & $\mathrm{X}$ & & & . & . & . & . & . \\
\hline Friday & Banned after 08/01/2014 & & & & & $\mathrm{X}$ & . & . & . \\
\hline Saturday & Always Allowed & $\mathrm{X}$ & $\mathrm{X}$ & $\mathrm{X}$ & $\mathrm{X}$ & 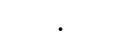 & 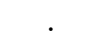 & 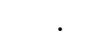 & . \\
\hline Sunday & Always Allowed & . & . & . & . & $\mathrm{X}$ & $\mathrm{X}$ & $\mathrm{X}$ & $\mathrm{X}$ \\
\hline & Total Watering Days & 3 & 2 & 1 & 1 & 3 & 2 & 1 & 1 \\
\hline
\end{tabular}

Notes: This table shows which days each household is permitted to use water outdoors both before and after the schedule change based on whether their house is odd- or even-numbered. On permitted days, marked with an X, households may use water outdoors but only before $9 \mathrm{am}$ in the morning or after $6 \mathrm{pm}$ in the evening. 
Table 3: Effect of Schedule Change on Water Consumption

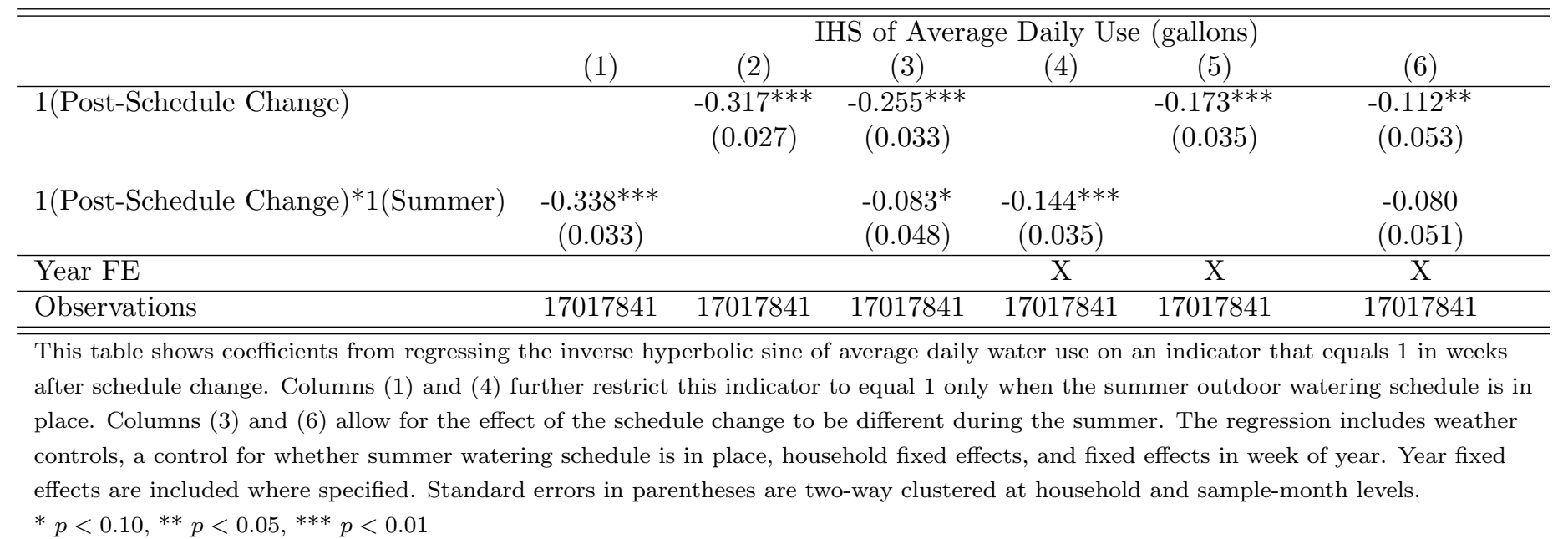


Table 4: Simultaneous Impact of City-wide Conservation Policies and Drought Interest on Water Use

\begin{tabular}{lcccc}
\hline \hline Dependent Variable & \multicolumn{3}{c}{ IHS of Average Daily Use (gallons) } \\
& $(1)$ & $(2)$ & $(3)$ & $(4)$ \\
\hline \multirow{2}{*}{ Panel A: Regression Coefficients } & & & & \\
IHS of Fixed Rate & $0.563^{* * *}$ & $0.810^{* * *}$ & & \\
& $(0.205)$ & $(0.203)$ & & \\
IHS of Marginal Rate per Gallon & $-0.164^{* * *}$ & -0.038 & & \\
& $(0.035)$ & $(0.044)$ & & \\
IHS of Average Rate per Gallon & & & $-0.388^{* * *}$ & $-0.367^{* * *}$ \\
& & & $(0.085)$ & $(0.133)$ \\
& & & & \\
& & & & \\
1(Post-Schedule Change)*1(Summer) & $-0.288^{* * *}$ & $-0.121^{* * *}$ & $-0.329^{* * *}$ & $-0.253^{* * *}$ \\
& $(0.030)$ & $(0.039)$ & $(0.032)$ & $(0.057)$ \\
Drought Interest & 0.006 & 0.018 & -0.001 & $0.028^{*}$ \\
& $(0.015)$ & $(0.013)$ & $(0.017)$ & $(0.016)$ \\
\hline
\end{tabular}

Panel B: Implied Elasticities

Marginal Rate per Gallon $\quad-0.16 \quad-0.04$

Average Rate per Gallon $\quad-0.39 \quad-0.37$

\begin{tabular}{lcccc}
\hline Year FE & \multicolumn{1}{c}{ X } & $\mathrm{X}$ \\
\hline Observations & 17017841 & 17017841 & 17017841 & 17017841 \\
\hline \hline
\end{tabular}

Notes: Each column presents regression estimates of the effect of city-level policies on the inverse hyperbolic sine (IHS) of average daily water use. Columns (1) and (2) include marginal and fixed rates, while columns (3) and (4) include average rates. Regressions include weather controls, household and week of year fixed effects. Columns (2) and (4) include year fixed-effects. Standard errors in parentheses are two-way clustered at household and sample-month levels. We compute elasticities using the following formula derived by Bellemare and Wichman (2020):

$\xi_{y x}=\hat{\beta} \cdot \frac{\bar{x} \cdot \sqrt{\bar{y}^{2}+1}}{\bar{y} \cdot \sqrt{\bar{x}^{2}+1}}$ where $\bar{x}$ is the mean of our independent variable and $\bar{y}$ is the mean of our dependent variable. ${ }^{*} p<0.10,{ }^{* *} p<0.05,{ }^{* * *} p<0.01$ 
Table 5: Policies' Contributions to Water Conservation

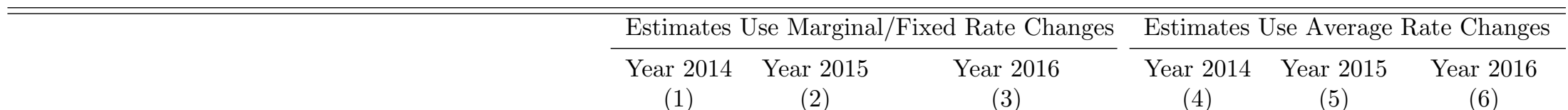

Panel A: Outcome: IHS of Water Use

Actual Change

$-0.101$

$-0.307$

$-0.323$

$-0.101$

$-0.307$

$-0.323$

Policy Induced Change

$-0.143^{* * *}$

$-0.306^{* * *}$

$-0.270^{* * *}$

(0.025)

$-0.193^{* * *}$

(0.023)

$-0.296^{* * *}$

(0.027)

$-0.309 * * *$

(0.023)

$99.7 \%$

$83.6 \%$

$191.1 \%$

$96.4 \%$

(0.034)

Policy-Induced Change / Actual Change

$141.6 \%$

Panel B: \% Actual Change Explained by Each Policy

Marginal and Fixed Rate Changes

$\begin{array}{ccc}50.30 * * * & 39.53^{* * *} & 39.99^{* * *} \\ (12.29) & (7.89) & (7.45)\end{array}$

Average Rate Changes

1(Post-Schedule Change)*1(Summer)

$\begin{array}{ccc}98.48^{* * *} & 63.30^{* * *} & 45.10^{* * *} \\ (10.26) & (6.60) & (4.70)\end{array}$

$\begin{array}{ccc}77.00^{* * *} & 23.75^{* * *} & 43.93^{* * *} \\ (16.82) & (5.19) & (9.60)\end{array}$

$\begin{array}{lll}-7.48 & -3.26 & -1.51\end{array}$

(4.12)

$\begin{array}{ccc}112.40^{* * *} & 72.24^{* * *} & 51.47^{* * *} \\ (10.92) & (7.02) & (-5.00)\end{array}$

Drought Interest

(20.45)

$(8.92)$

1.17

0.51

0.24

Notes: The top panel of this table shows the actual and predicted policy-induced change in the inverse hyperbolic sine (IHS) of average daily water use each year relative to the beginning of the sample period in the first semester of 2013. The policy-induced change is computed using the regression coefficients in column (1) of Table 4 for estimates using marginal/fixed rates and column (3) of Table 4 for estimates using average rates. The bottom panel shows contribution of each city-wide policy to the total actual change. Standard errors in parentheses are two-way clustered at sample-month and household levels. ${ }^{*} p<0.10,{ }^{* *} p<0.05,{ }^{* * *} p<0.01$ 


\section{Appendix Figures}

Figure A.1: Precipitation and High Temperature in Fresno and California
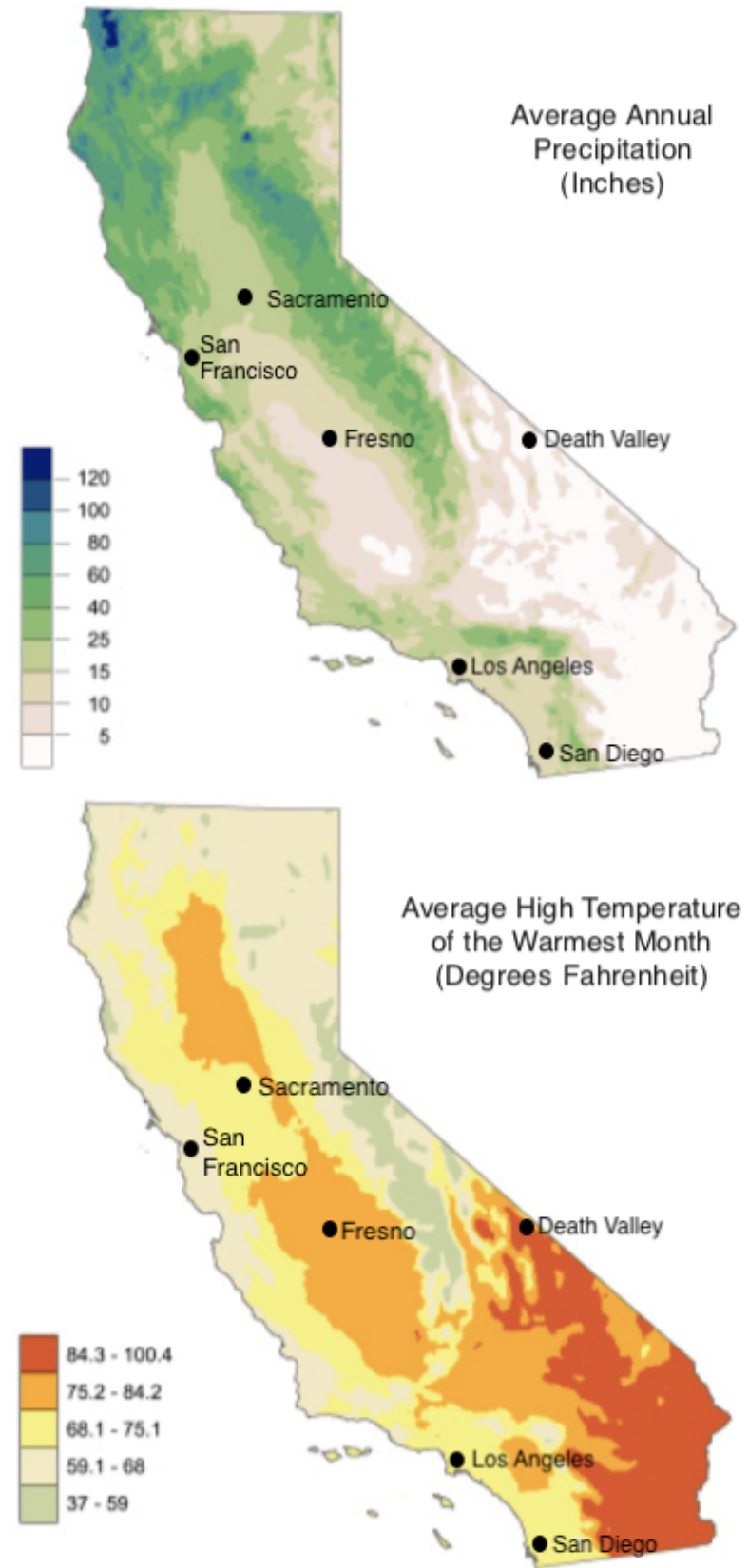

Notes: Source of map is the California Coastal Commission (https://www.coastal.ca.gov/ coastalvoices/resources/Biodiversity_Atlas_Climate_and_Topography.pdf, accessed on April 2, 2019) 
Figure A.2: Rebate Adoption Over Time

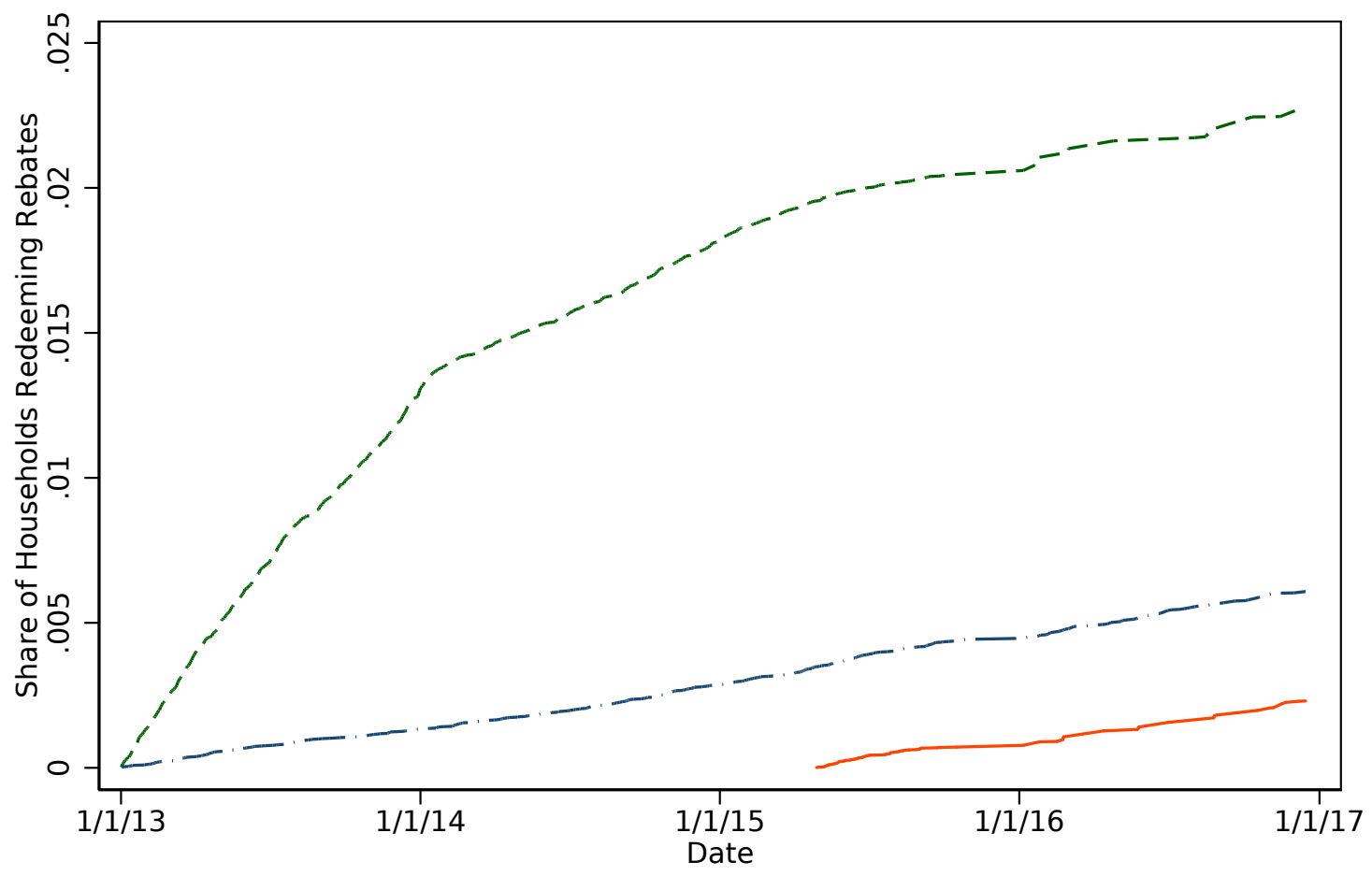

- - - - - Clothes Washer — Lawn Replacement _ - - - Toilet

Notes: This plot shows the cumulative share of sample households issued a clothes washer, lawn replacement or toilet rebate over the sample period. Lawn replacement rebates were introduced in 2015. 
Figure A.3: Fines, Timer Tutorials, and Audits Issued in Fresno

(a) Share of Households Receiving Fines

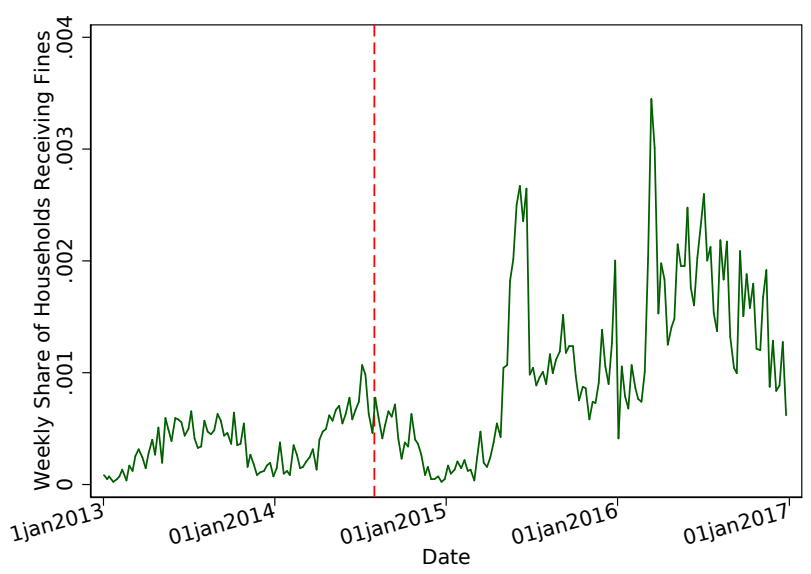

(b) Share of Households Receiving Timer Tutorials

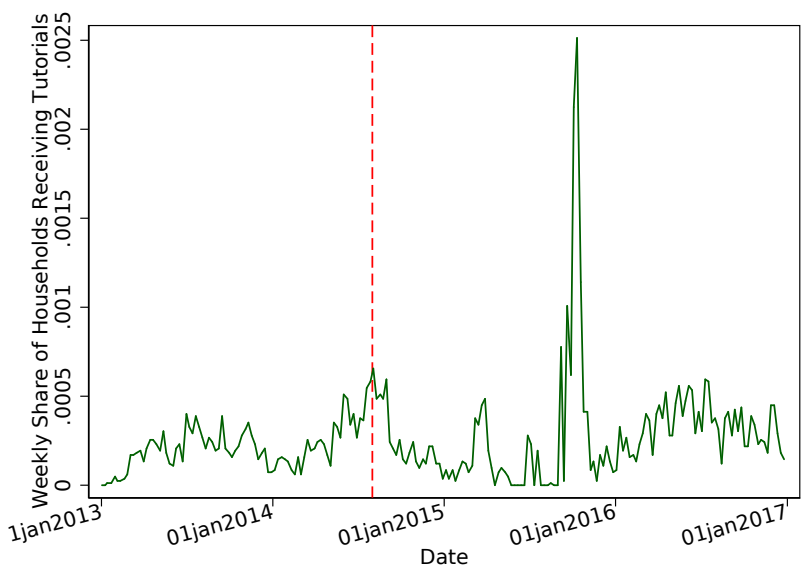

(c) Share of Households Receiving Audits

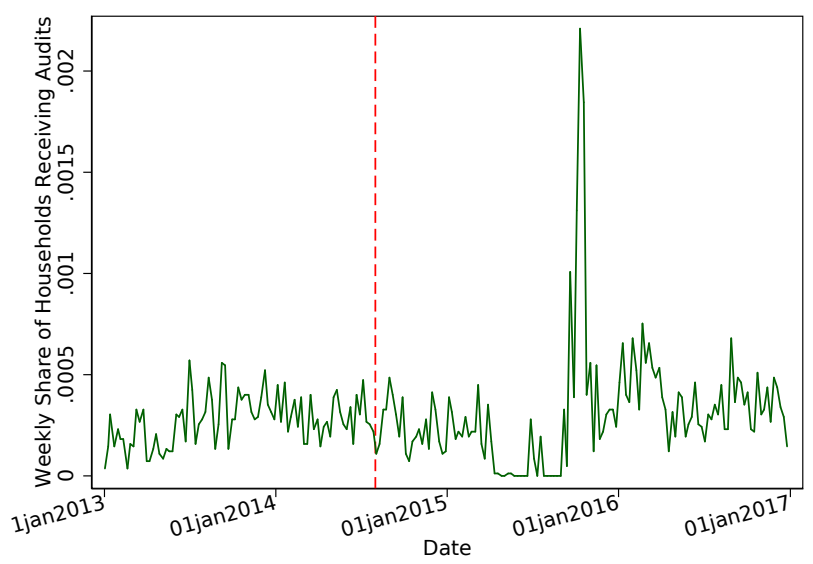

Notes: The top, middle and bottom figures respectively show the weekly share of households in our sample that received fines, timer tutorials, and audits issued in Fresno throughout the sample period. The red line is the date of the schedule change on August 1, 2014. 


\section{Appendix Tables}

Table A.1: Summary Statistics

\begin{tabular}{lccc}
\hline \hline & California & Fresno & Rank in California \\
\hline & & & \\
Demographics & $35,984,596$ & 506,132 & 5 \\
Population & 88,595 & 58,219 & 90 \\
Average household income & 61,933 & 41,455 & 96 \\
Median household income & $30.43 \%$ & $20.10 \%$ & 69 \\
Fraction of bachelor's degree or more & 3.04 & 3.10 & 43 \\
Average household size & $54.69 \%$ & $46.06 \%$ & 80 \\
Fraction of home-owners & & & \\
& & & \\
Average Per Capita Residential Water Use (gal/day) & 145 & 140 & 27 \\
Year 2013 & 129 & 122 & 34 \\
Year 2014 & 98 & 105 & 22 \\
Year 2015 & 97 & 120 & \\
Year 2016 & & & \\
& & & \\
Climate Characteristics (2013-2016) & 0.0529 & 0.0367 & 73 \\
Average Precipitation (inches/day) & 76.00 & 80.94 & 50 \\
Average Daily High Temperature (F) & 53.10 & 53.69 & \\
Average Daily Low Temperature (F) & & \\
\hline \hline
\end{tabular}

Notes: This table shows summary statistics on demographics, average water use and climate in California and Fresno.

It also shows Fresno's rank within the 100 largest water utilities in California with regard to water use and its rank among the 100 largest Census locations with regard to demographics and climate. Demographics data are from 2014 ACS 5-year estimates. Income-related statistics are in 2014 inflation-adjusted dollar. Average per capita daily water use data is from California State Water Resources Control Board. (Accessed at https://www . waterboards.ca.gov/water_issues/programs/conservation_portal/conservation_reporting.html on April 2, 2019). Most weather data before October 2014 is imputed. Aggregate California weather estimates are averaged across the 100 most populous Census places, accounting for $59.6 \%$ of the state's population over 2013-2016. Climate characteristics are from NOAA National Climatic Data Center (Accessed at https://www.ncdc.noaa.gov/cdo-web/search on April 3, 2019). 
Table A.2: Simultaneous Impact of City-wide Conservation Policies and Drought Interest on Water Use, Year-Round Schedule Change Effects

\begin{tabular}{|c|c|c|c|c|}
\hline \multirow[t]{2}{*}{ Dependent Variable } & \multicolumn{4}{|c|}{ IHS of Average Daily Use (gallons) } \\
\hline & $(1)$ & $(2)$ & $(3)$ & $(4)$ \\
\hline \multicolumn{5}{|l|}{ Panel A: Regression Coefficients } \\
\hline IHS of Fixed Rate & $\begin{array}{l}0.399^{* *} \\
(0.157)\end{array}$ & $\begin{array}{l}0.344^{* *} \\
(0.158)\end{array}$ & & \\
\hline IHS of Marginal Rate per Gallon & $\begin{array}{c}-0.165^{* * *} \\
(0.028)\end{array}$ & $\begin{array}{c}-0.388^{* * *} \\
(0.070)\end{array}$ & & \\
\hline IHS of Average Rate per Gallon & & & $\begin{array}{c}-0.401^{* * *} \\
(0.071)\end{array}$ & $\begin{array}{c}-1.346^{* * *} \\
(0.243)\end{array}$ \\
\hline 1(Post-Schedule Change) & $\begin{array}{c}-0.266^{* * *} \\
(0.032)\end{array}$ & $\begin{array}{c}-0.529^{* * *} \\
(0.091)\end{array}$ & $\begin{array}{c}-0.288^{* * *} \\
(0.039)\end{array}$ & $\begin{array}{c}-0.974^{* * *} \\
(0.148)\end{array}$ \\
\hline 1 (Post-Schedule Change) $* 1$ (Summer) & $\begin{array}{l}-0.017 \\
(0.043)\end{array}$ & $\begin{array}{c}0.011 \\
(0.040)\end{array}$ & $\begin{array}{l}-0.028 \\
(0.050)\end{array}$ & $\begin{array}{c}0.056 \\
(0.042)\end{array}$ \\
\hline Drought Interest & $\begin{array}{l}-0.009 \\
(0.009)\end{array}$ & $\begin{array}{c}0.003 \\
(0.012)\end{array}$ & $\begin{array}{l}-0.012 \\
(0.012)\end{array}$ & $\begin{array}{l}-0.007 \\
(0.013)\end{array}$ \\
\hline
\end{tabular}

Panel B: Implied Elasticities

Marginal Rate per Gallon $\quad-0.17 \quad-0.39$

Average Rate per Gallon $\quad-0.40 \quad-1.35$

\begin{tabular}{lcccc}
\hline Year FE & & $\mathrm{X}$ & $\mathrm{X}$ \\
\hline Observations & 17017841 & 17017841 & 17017841 & 17017841 \\
\hline \hline
\end{tabular}

Notes: Each column presents regression estimates of the effect of city-level policies on the inverse hyperbolic sine (IHS) of average daily water use. Columns (1) and (2) include marginal and fixed rates, while columns (3) and (4) include average rates. Regressions include weather controls, and household and week of year fixed effects. Columns (2) and (4) include year fixed-effects. Standard errors in parentheses are two-way clustered at household and sample-month levels. We compute elasticities using the following formula derived by Bellemare and Wichman (2020): $\xi_{y x}=\hat{\beta} \cdot \frac{\bar{x} \cdot \sqrt{\bar{y}^{2}+1}}{\bar{y} \cdot \sqrt{\bar{x}^{2}+1}}$ where $\bar{x}$ is the mean of our independent variable and $\bar{y}$ is the mean of our dependent variable.

${ }^{*} p<0.10,{ }^{* *} p<0.05,{ }^{* * *} p<0.01$ 
Table A.3: Simultaneous Impact of City-wide Conservation Policies and Drought Interest on Log Water Use

\begin{tabular}{|c|c|c|c|c|}
\hline \multirow{2}{*}{ Dependent Variable } & \multicolumn{4}{|c|}{ Log of (1+Average Daily Use(gal)) } \\
\hline & (1) & (2) & $(3)$ & (4) \\
\hline Log of Fixed Rate & $\begin{array}{c}0.422^{* * *} \\
(0.145)\end{array}$ & $\begin{array}{c}0.555^{* * *} \\
(0.148)\end{array}$ & & \\
\hline Log of Marginal Rate per Gallon & $\begin{array}{c}-0.183^{* * *} \\
(0.025)\end{array}$ & $\begin{array}{l}-0.052 \\
(0.035)\end{array}$ & & \\
\hline Log of Average Rate per Gallon & & & $\begin{array}{c}-0.351^{* * *} \\
(0.057)\end{array}$ & $\begin{array}{c}-0.242^{* *} \\
(0.093)\end{array}$ \\
\hline 1 (Post-Schedule Change) $* 1$ (Summer) & $\begin{array}{c}-0.292^{* * *} \\
(0.024)\end{array}$ & $\begin{array}{c}-0.144^{* * *} \\
(0.036)\end{array}$ & $\begin{array}{c}-0.322^{* * *} \\
(0.026)\end{array}$ & $\begin{array}{c}-0.218^{* * *} \\
(0.044)\end{array}$ \\
\hline Drought Interest & $\begin{array}{c}0.017 \\
(0.013) \\
\end{array}$ & $\begin{array}{c}0.011 \\
(0.010)\end{array}$ & $\begin{array}{c}0.008 \\
(0.014) \\
\end{array}$ & $\begin{array}{c}0.013 \\
(0.012)\end{array}$ \\
\hline Year FE & & $\mathrm{X}$ & & $\mathrm{X}$ \\
\hline Observations & 17017841 & 17017841 & 17017841 & 17017841 \\
\hline
\end{tabular}

Notes: This table calculates the same results as Table 4, except using the

$\log (1+$ average daily water use $)$ rather than the IHS. Each column presents regression estimates of the effect of city-level policies on the log of average daily water use. Columns (1) and (2) include marginal and fixed rates, while columns (3) and (4) include average rates. Regressions include weather controls, and household and week of year fixed effects. Columns (2) and (4) include year fixed-effects. Standard errors in parentheses are two-way clustered at household and sample-month levels. ${ }^{*} p<0.10,{ }^{* *} p<0.05,{ }^{* * *} p<0.01$ 
Table A.4: Policies' Contributions to Water Conservation, Year-Round Schedule Change Effects

\begin{tabular}{|c|c|c|c|c|c|c|}
\hline & \multicolumn{3}{|c|}{ Estimates Use Marginal/Fixed Rate Changes } & \multicolumn{3}{|c|}{ Estimates Use Average Rate Changes } \\
\hline & $\begin{array}{c}\text { Year } 2014 \\
(1)\end{array}$ & $\begin{array}{c}\text { Year } 2015 \\
(2)\end{array}$ & $\begin{array}{c}\text { Year } 2016 \\
(3)\end{array}$ & $\begin{array}{c}\text { Year } 2014 \\
(4)\end{array}$ & $\begin{array}{c}\text { Year } 2015 \\
(5)\end{array}$ & $\begin{array}{c}\text { Year } 2016 \\
(6)\end{array}$ \\
\hline \multicolumn{7}{|l|}{ Panel A: Outcome: IHS of Water Use } \\
\hline Actual Change & -0.101 & -0.307 & -0.323 & -0.101 & -0.307 & -0.323 \\
\hline Policy Induced Change & $\begin{array}{c}-0.189^{* * *} \\
(0.017)\end{array}$ & $\begin{array}{c}-0.399 * * * \\
(0.021)\end{array}$ & $\begin{array}{c}-0.407^{* * *} \\
(0.027)\end{array}$ & $\begin{array}{c}-0.234^{* * *} \\
(0.016)\end{array}$ & $\begin{array}{c}-0.404^{* * *} \\
(0.023)\end{array}$ & $\begin{array}{c}-0.459^{* * *} \\
(0.034)\end{array}$ \\
\hline Policy-Induced Change / Actual Change & $187.1 \%$ & $130 \%$ & $126 \%$ & $231.7 \%$ & $131.6 \%$ & $142.1 \%$ \\
\hline
\end{tabular}

Panel B: \% Actual Change Explained by Each Policy

Marginal and Fixed Rate Changes

$\begin{array}{ccc}52.59^{* * *} & 34.45^{* * *} & 38.40^{* * *} \\ (10.23) & (5.34) & (5.50)\end{array}$

Average Rate Changes

Schedule Change

$122.20^{* * *} \quad 90.61^{*} *$

(10.06) $\quad(7.03)$

$85.17^{* * *}$

$(6.56)$

$79.60^{* * *} \quad 24.55^{* * *}$

$45.42^{* * *}$

$\begin{array}{lll}(14.16) & (4.37) \quad(8.08)\end{array}$

Schedule Change

$116.2^{* * *} \quad 86.79^{* * *}$

1(Post-Schedule Change)

(13.94) (10.41)

$82.45^{* * *}$

(9.89)

$135.00^{* * *}$

$99.79^{* * *}$

$93.35^{* * *}$

(10.31) (7.36)

(7.26)

1(Post-Schedule Change)*1(Summer)

$\begin{array}{cc}5.95 & 3.82 \\ (14.59) & (9.38)\end{array}$

2.72

(6.68)

$125.50^{* * *}$

$93.69^{* * *}$

$89.00^{* * *}$

(17.01) (12.70)

(12.06)

$11.61 \quad 5.07$

(12.40)

(5.41)

2.34

(17.03)

6.11

4.35

Drought Interest

(2.50)

16.40

(7.80)

Notes: The top panel of this table shows the actual and predicted policy-induced change in the inverse hyperbolic sine (IHS) of average daily water use each year relative to the beginning of the sample period in the first semester of 2013. The policy-induced change is computed using the regression coefficients in column (1) of Table A.2 for estimate using marginal/fixed rates and column (3) of Table A.2 for estimates using average rates. The bottom panel shows contribution of each citywide policy to the total actual change. Standard errors in parentheses are two-way clustered at sample-month and household levels. ${ }^{*} p<0.10,{ }^{* *} p<0.05,{ }^{* * *} p<0.01$ 